Portland State University

PDXScholar

1983

\title{
Serial cardiovascular adaptations during pregnancy
}

Mark Vincent Hart

Portland State University

Follow this and additional works at: https://pdxscholar.library.pdx.edu/open_access_etds

Part of the Biology Commons, Cardiology Commons, and the Cardiovascular System Commons Let us know how access to this document benefits you.

\section{Recommended Citation}

Hart, Mark Vincent, "Serial cardiovascular adaptations during pregnancy" (1983). Dissertations and Theses. Paper 3354.

https://doi.org/10.15760/etd.5011

This Thesis is brought to you for free and open access. It has been accepted for inclusion in Dissertations and Theses by an authorized administrator of PDXScholar. Please contact us if we can make this document more accessible: pdxscholar@pdx.edu. 
AN ABSTRACT OF THE THESIS OF Mark Vincent Hart for the Master of Science in Biology presented August 12, 1983.

Title: Serial Cardiovascular Adaptations During Pregnancy

APPROVED BY MEMBERS OF THE THESIS COMMITTEE:

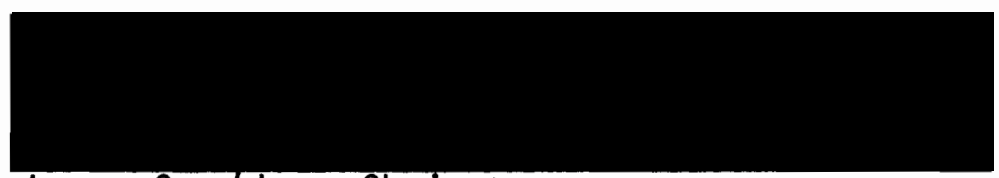

Larry Crawshaw, Chairman
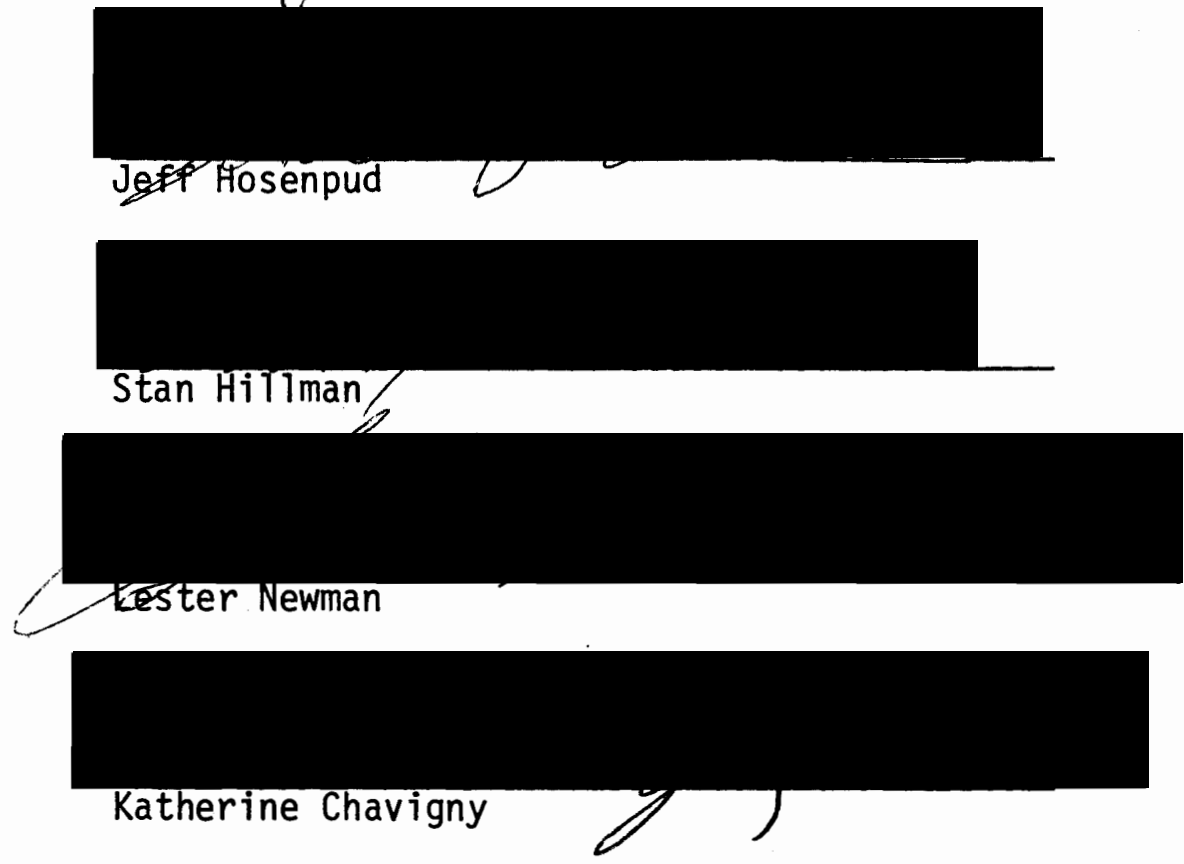

Maternal cardiovascular adaptations appear to be essential in order to supply extra circulation to both the developing fetus and maternal system during a successful pregnancy. Since inadequate cardiovascular adjustments may produce abortions or maternal morbidity, the characterization of maternal cardiovascular changes during pregnancy and the elaboration of the underlying mechanism for these changes are essential 
to the understanding of how the heart enlarges during pregnancy and what significance this enlargement might have. To provide needed information regarding this time course and extent of maternal cardiac enlargement and the hormonal and hemodynamic changes which may be responsible for these changes, the guinea pig was used as an animal model to characterize the maternal cardiac, hemodynamic and hormonal changes during early, mid and late pregnancy.

All animals used were virgin female guinea pigs which were prospectively weight-matched and randomly assigned to one of the following groups: 1) Control, 2) Pregnant(20 Days), 3) Pregnant (40 Days), and 4) Pregnant (60 Days). The sows assigned to the pregnant groups were housed with a boar during estrus to provide a dated pregnancy. On the day of study, each animal was anesthetized and polyvinyl catheters were placed in the left ventricle, right atrium and abdominal aorta. The animals were allowed to recover from the anesthesia and were then placed in a limited restraint cage where simultaneous pressures were recorded. Cardiac output and regional blood flows were then measured by radioactive microspheres indicator dilution technique, arterial blood gas samples were taken, blood volume was measured by a dye dilution technique using Evans Blue, and estrogen and progesterone plasma levels were determined by radioimmunoassay. After all in vivo measurements were obtained, the animals were sacrificed and the in vitro left ventricular pressure-volume relations were measured in 14 control and 39 pregnant guinea pigs.

Arterial blood gases and hematocrits obtained at the end of the study were similar to those previously reported in control animals. 
Kidney weights, wet lung weights and left ventricular weights were unchanged during pregnancy despite a significant increase in total maternal weight. Hemodynamic data from the control and pregnant guinea pigs demonstrated that there was no statistical difference in heart or respiratory rates, or in aortic, right atrial or left ventricular end-diastolic pressures. Total cardiac output was increased as early as Day 20 of gestation but then gradually returned to pre-pregnant values. Uterine blood flow was not increased until Day 40 when fetal and placental weights were increased. Since heart rates were unchanged, stroke volume was increased by Day 20 and remained elevated throughout pregnancy. Blood volume steadily increased during pregnancy, reaching a peak value at the end of gestation. The in vitro pressure-volume relationships of the left ventricles demonstrated that the curves of the pregnant animals were shifted to the right as early as Day 20 and progressively increased with a peak increase in volume occurring at end gestation. This increase occurred without a change in left ventricular weight, therefore increasing the radius:wall thickness ratio throughout pregnancy. There was no change in left ventricle mechanical or material properties indicating that left ventricular enlargement occurs by geometric remodeling. Estradiol plasma levels slowly increased during pregnancy but were not significantly elevated until Day 40 of gestation. Estrone was only elevated at Day 40 and returned again by Day 60 , while progesterone was significantly increased throughout pregnancy with a peak value occurring at Day 40.

In summary, significant cardiovascular changes are seen during early pregnancy and occur prior to a major increase in uterine blood flow. These cardiovascular alterations may be mediated by changing hormone levels. 
SERIAL CARDIOVASCULAR ADAPTATIONS

DURING PREGNANCY

by

MARK VINCENT HART

A thesis submitted in partial fulfillment of the requirements for the degree of

\author{
MASTER OF SCIENCE \\ in \\ BIOLOGY
}

Portland State University

1983 
TO THE OFFICE OF GRADUATE STUDIES AND RESEARCH:

The members of the Committee approve the thesis of Mark Vincent Hart presented August 12, 1983.

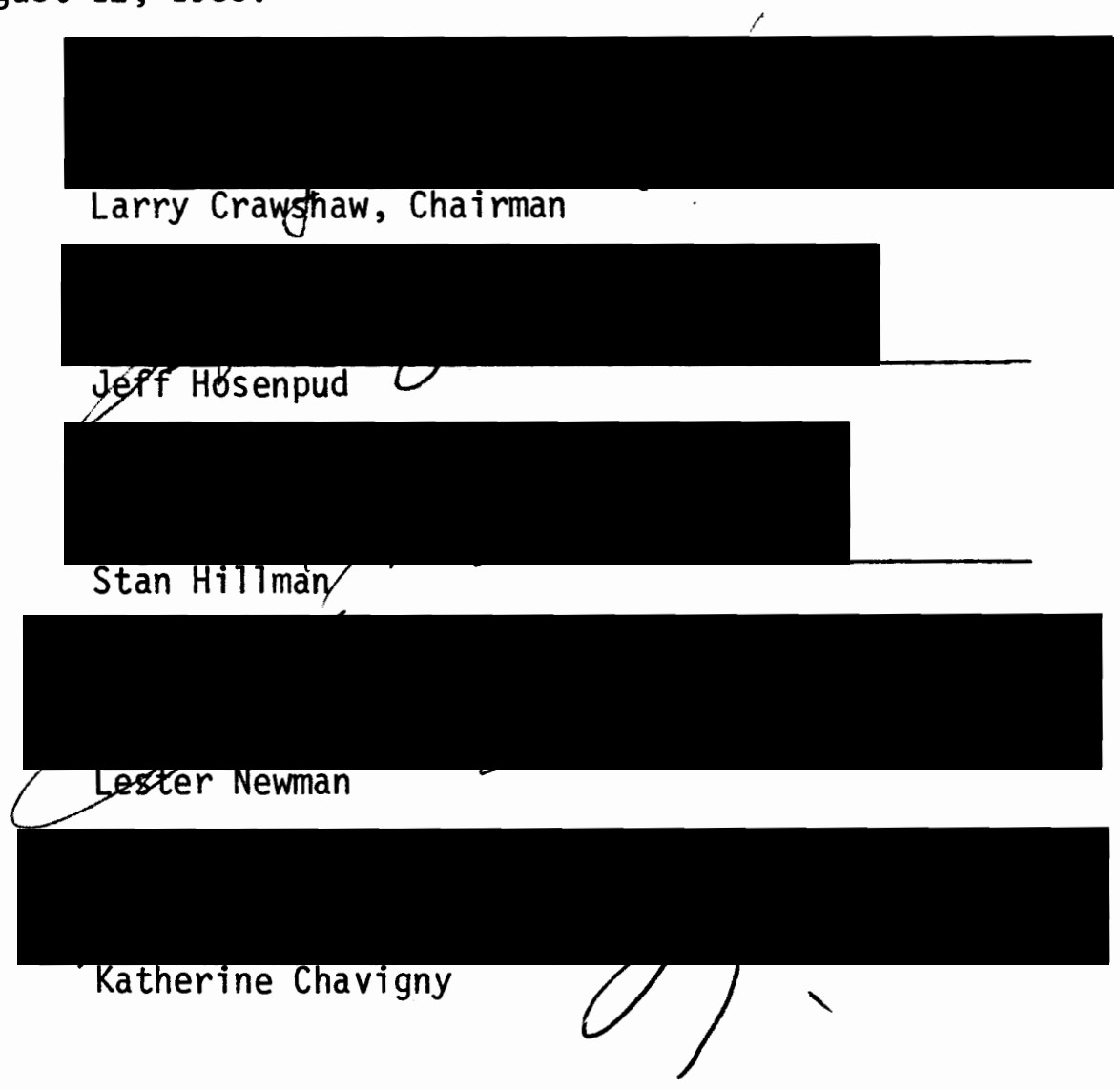

APPROVED :

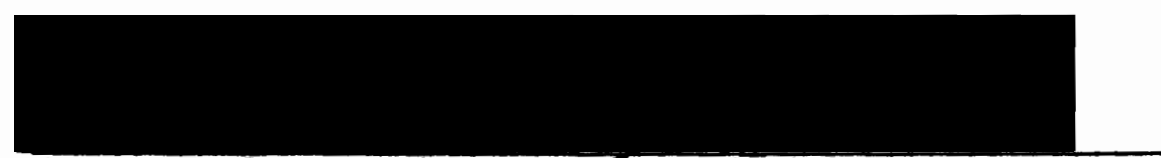

Herman Taylor, Head, Depaetrient of Biology

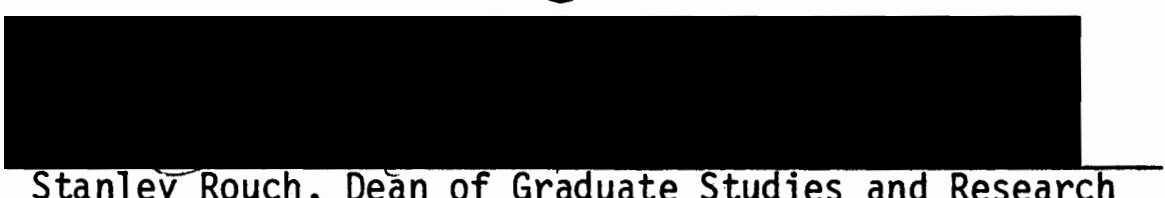

Stanley Rouch, Dean of Graduate Studies and Research 


\section{ACKNOWLEDGEMENTS}

I would like to express my appreciation and acknowledge the assistance that many people have provided during this study. Drs. Jeff Hosenpud and Mark Morton contributed a good deal of their time to the experimental design and implementation of this study, and provided much needed advice during the preparation of this thesis. Dr. James Metcalfe kindly allowed me to perform my graduate research in the Heart Research Laboratory, and the staff of the lab provided assistance and support during the study. Specifically, I would like to thank Sharon Knopp, Cathy Chase and J. Eugene Welch for their assistance in animal breeding, data acquisition and blood gas analysis; Lynn Bentson for her help with the statistical analysis of the data; and Jackie Niemi for typing the drafts and final copy of this thesis. The hormone analysis was performed by Dr. John Resko's laboratory in the Department of Physiology at OHSU.

Finally, this project was financially supported by the Medical Research Foundation of Oregon, N. L. Tartar Research Fellowship Fund and Public Health Service grant \#HD-10034. 
TABLE OF CONTENTS

Page

ACKNOWLEDGEMENTS $\ldots \ldots \ldots \ldots \ldots \ldots \ldots \ldots \ldots \ldots \ldots \ldots \ldots \ldots \ldots \ldots \ldots \ldots \ldots \ldots$

LIST OF TABLES $\ldots \ldots \ldots \ldots \ldots \ldots \ldots \ldots \ldots \ldots \ldots \ldots \ldots \ldots \ldots \ldots \ldots \ldots \ldots$

LIST OF FIGURES $\ldots \ldots \ldots \ldots \ldots \ldots \ldots \ldots \ldots \ldots \ldots \ldots \ldots \ldots \ldots \ldots \ldots \ldots \ldots \ldots$

CHAPTER

I INTRODUCTION $\ldots \ldots \ldots \ldots \ldots \ldots \ldots \ldots \ldots \ldots \ldots \ldots \ldots \ldots \ldots \ldots$

II REVIEW OF LITERATURE $\ldots \ldots \ldots \ldots \ldots \ldots \ldots \ldots \ldots \ldots \ldots \ldots \ldots$

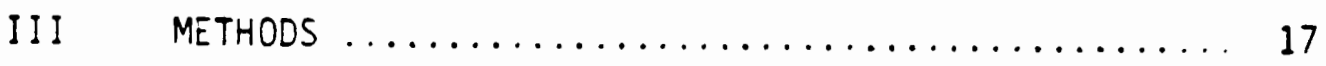

Experimental animal selection ............ 17

Animal preparation and instrumentation ...... 17

Study protocol ........................ 20

In vivo pressure measurements

Cardiac output and organ blood flow

Blood gas analys is

Hormone analys is

Blood volume measurements

In vitro pressure-volume curves

Autopsy data

Effects of anesthesia

Data analysis

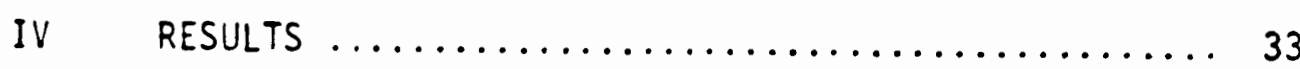

Animal well-being $\ldots \ldots \ldots \ldots \ldots \ldots \ldots . \ldots . \ldots . \ldots 33$

In vivo pressure measurements $\ldots \ldots \ldots \ldots \ldots . . \ldots 9$

Cardiac output and regional blood flow ....... 39

Hormone data ........................... 39

Blood volume data ..................... 42

Pressure-volume data $\ldots \ldots \ldots \ldots \ldots \ldots \ldots . \ldots 2$ 
DISCUSSION

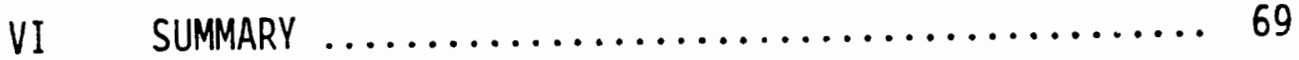




\section{LIST OF TABLES}

Table

Page

I Summary of cardiovascular alterations during

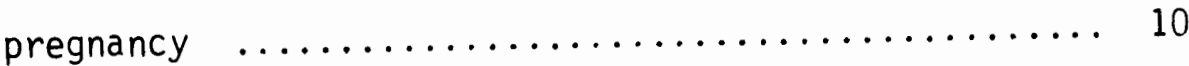

II Body and organ weights $\ldots \ldots \ldots \ldots \ldots \ldots \ldots \ldots, 34$

II Arterial blood gas data $\ldots \ldots \ldots \ldots \ldots \ldots \ldots \ldots . \ldots \ldots$

IV Anesthesia recovery $\ldots \ldots \ldots \ldots \ldots \ldots \ldots \ldots \ldots, 36$

V Hemodynamic data $\ldots \ldots \ldots \ldots \ldots \ldots \ldots \ldots \ldots \ldots, 40$

VI Cardiac output and regional blood flow $\ldots \ldots \ldots \ldots, 41$

VII Hormone levels during pregnancy $\ldots \ldots \ldots \ldots \ldots \ldots . \ldots 3$

VIII Blood volume and hematocrit ............... 44

IX Left ventricular dimensions $\ldots \ldots \ldots \ldots \ldots \ldots \ldots . \ldots 2$

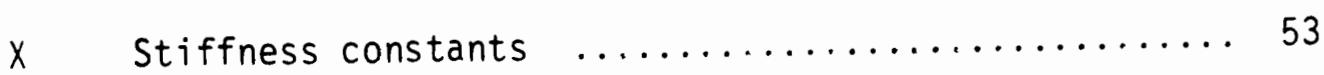




\section{LIST OF FIGURES}

Figure

Page

1 Effect of gestational age and posture on cardiovascular hemodynamics during pregnancy $\ldots \ldots \ldots \ldots .6$

2 In vitro pressure volume curve of control and end gestation guinea pigs $\ldots \ldots \ldots \ldots \ldots \ldots \ldots \ldots \ldots . \ldots$

3 In vitro pressure volume curves of hormone treated

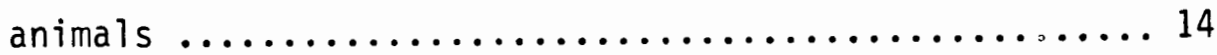

$4 \quad$ Hormone profiles $\ldots \ldots \ldots \ldots \ldots \ldots \ldots \ldots \ldots \ldots \ldots$

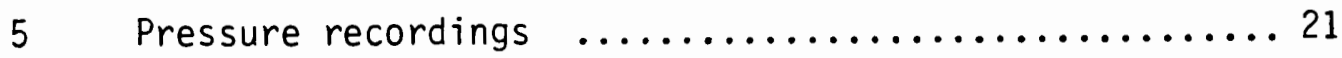

6 Apparatus for pressure volume measurements $\ldots \ldots \ldots 27$

$7 \quad$ Anesthesia recovery $\ldots \ldots \ldots \ldots \ldots \ldots \ldots \ldots \ldots \ldots \ldots \ldots \ldots$

$8 \quad$ Blood volume $\ldots \ldots \ldots \ldots \ldots \ldots \ldots \ldots \ldots \ldots \ldots \ldots$

9 Pressure volume recording $\ldots \ldots \ldots \ldots \ldots \ldots \ldots \ldots$

10 Pressure volume curve $\ldots \ldots \ldots \ldots \ldots \ldots \ldots \ldots . \ldots 48$

11 Linear pressure volume relations $\ldots \ldots \ldots \ldots \ldots \ldots$

12 strss-elastic modulus $\ldots \ldots \ldots \ldots \ldots \ldots \ldots \ldots \ldots \ldots$

13 Cardiac output, stroke volume and heart rate during

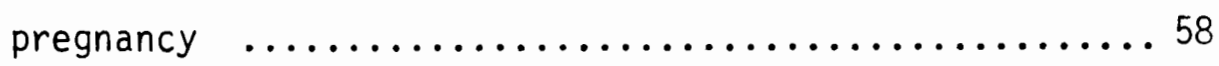

14 Heart size and stroke volume $\ldots \ldots \ldots \ldots \ldots \ldots . \ldots 6$

15 Hormonal alterations during pregnancy $\ldots \ldots \ldots \ldots 66$ 


\section{INTRODUCTION}

The cardiovascular changes observed during the course of mammalian pregnancy are among the most extreme alterations seen in non-pathological states. These maternal cardiovascular adaptations appear to be essential in order to supply extra circulation to both the developing fetus and maternal system during a successful pregnancy. Fetal development may be retarded, or abortion may ensue when maternal cardiovascular adjustments are inadequate. The interaction of coexisting maternal cardiovascular pathophysiology with gestational cardiovascular changes may produce important maternal morbidity. Therefore, the characterization of maternal cardiovascular changes during pregnancy and the elaboration of the underlying mechanism for these changes are essential to the understanding of how the heart enlarges during pregnancy and what significance this enlargement might have.

This study will attempt to provide needed information regarding the time course and extent of maternal cardiac enlargement and the hormonal and hemodynamic changes which may be responsible for these changes. To accomplish this goal, the guinea pig was used as an animal model to 1) characterize the maternal cardiac, hemodynamic and hormonal changes during early, mid and late pregnancy, and 2) correlate the changes in heart size with hemodynamic and hormonal values to evaluate the mechanisms that may be responsible for cardiac enlargement during pregnancy. 


\section{REVIEW OF THE LITERATURE}

Most of the work investigating the maternal cardiovascular adaptations to pregnancy has been carried out in humans. Some of the studies date back over 150 years ago, and despite the limitations of early techniques and experimental designs, these early studies lead to important clinical findings and helped provide a direction for future investigations.

As early as 1825, a French physician who was serving as an intern in the Paris Maternity Hospital observed that the left ventricle of the maternal heart was hypertrophied during normal pregnancy (42). Larcher examined 130 hearts of patients who had died of childbed fever and were assumed to have been healthy prior to their fever. From these examinations, Larcher concluded that 1) the heart is normally enlarged during pregnancy, 2) the enlargement affects almost exclusively the left ventricle, 3) that the left ventricle increases from a minimum of one-quarter the normal thickness to one-third, 4) this enlargement consistently occurs, and 5) that the enlargement disappears during lactation. In Angus Macdonald's "The Bearings of Chronic Disease of the Heart on Pregnancy" (42) which was published in 1878, Macdonald follows a succession of studies which generally concur with Larcher's observations of left ventricular hypertrophy. All of these studies dealt mostly with anatomical considerations with very limited discussions of causation. Despite the limited emperical information that was available in the late 1870's, Macdonald made the following statement. 
It is plain that, as the amount of blood circulating within the mother's vessels during the latter months of pregnancy is increased beyond question, the same must be true of the amount circulating in the heart within a given period of time, since the heart is only a section of the general vascular system, unless it could be shown that the heart beats more quickly during the latter months of pregnancy than at other times. But the latter is not the fact; therefore it follows that at each contraction of the heart a larger amount than normal must be propelled from the ventricles, and at each diastole a larger amount must find its way to these cavities.... There is therefore reason to believe that in the left ventricle, during pregnancy, we have as a physiological condition a certain degree of increase in its capacity, associated with a variable amount of muscular hypertrophy in its walls. (Macdonald, Chapter 2, 1878)

The above statement was based primarily on clinical observations since it was another 35 years until cardiac output was measured during pregnancy by Lindhard in 1915 (41). He used a nitrous oxide method to determine cardiac output before, during and after pregnancy and observed a $50 \%$ increase during pregnancy with a return to pre-pregnant levels after pregnancy.

In 1926, Stander (79) suspected that the increase in the size of the uterus during pregnancy might be associated with an increased cardiac output. This investigator employed the Fick principle in awake dogs to measure "minute volume", or the amount of blood which passes through the lungs per minute, by calculating the total oxygen consumed and the arteriovenous oxygen content difference. From this study he observed a $33-50 \%$ increase in pregnant compared to nonpregnant dogs. He found most of this increase to take place during the latter half of pregnancy and attributed it to increased uteroplacental circulation. He also noted that during the estrus cycle, the dogs' cardiac output was increased though not to the levels he observed during pregnancy. 
Until the advent of cardiac catheterization, the cardiac output of humans was restricted to indirect gas methods. These studies (12, $13,41,80$ ) demonstrated a variable increase of $30 \%$ to $85 \%$ in resting cardiac output during gestation. In 1955, Bader et al. (4) published a study in which 46 normal pregnant women underwent cardiac catheterization to obtain cardiac output and right heart pressures. Each patient was studied only once during pregnancy. The women were divided into five groups from 14-40 weeks of gestation. Cardiac output was measured by the Fick principle with blood being simultaneously obtained from the pulmonary and brachial arteries for determination of oxygen content while oxygen consumption was being measured. The average resting cardiac output was elevated from the fourteenth to the thirtieth weeks with a peak occurring during the twenty-fifth through the twenty-seventh weeks of gestation which was $40 \%$ over normal values which had been demonstrated in earlier studies. Cardiac output fell toward normal values later in pregnancy which confirmed earlier serial study findings $(1,13)$.

By the 1960 's, most authorities agreed that cardiac output increased during pregnancy $30 \%$ to $50 \%$ but there was uncertainty as to the time course of these alterations. In 1969, Ueland et al. (83) performed a serial study on the same patients to eliminate the wide variation between individuals and evaluate the magnitude of the changes in cardiac output, heart rate, and stroke volume during pregnancy. The time sequence of these changes and the influence of maternal posture at different stages of pregnancy were also evaluated. Serial cardiovascular studies were performed in eleven normal women twice at various 
stages of pregnancy and once again postpartum. Figure 1 demonstrates their results. It is apparent that cardiac output was elevated early in pregnancy and maintained through the thirty-second week, then began to return towards normal values. An increase in stroke volume occurred quite early, but later in pregnancy stroke volume fell as heart rate increased.

The alterations in cardiac output in normal pregnancy do not demonstrate conclusive information concerning the mechanism by which stroke volume is increased. None of the known determinants of stroke volume, preload, contractility or afterload $(25,63)$ appear to change significantly during pregnancy.

Numerous studies have demonstrated a 40 to $50 \%$ increase in blood volume during pregnancy $(5,33,66,83)$ suggesting that increased preload (end-diastolic sarcomere length) may be a factor in increased cardiac output. Despite this increased blood volume, studies (4) have shown that right-sided filling pressures are not elevated during pregnancy. In addition, recent evidence has been presented that shows that the left ventricle in supine humans may actually work near the peak of its function curve at normal filling pressures (62). Infusions of whole blood or dextran $(10,73)$ in amounts sufficient to double left ventricular filling pressure have shown only minor changes in the dimensions of the normal left ventricle, stroke volume or cardiac output. This evidence suggests that an increase in preload from increased blood volume can contribute little to increased stroke volume during pregnancy. Non-invasive measurements of contractility, such as systolic time intervals and echocardiography have been used as a means of assessing 
Figure 1. The effect of gestational age and maternal posture on the cardiovascular parameters of eleven women during pregnancy and postpartum.

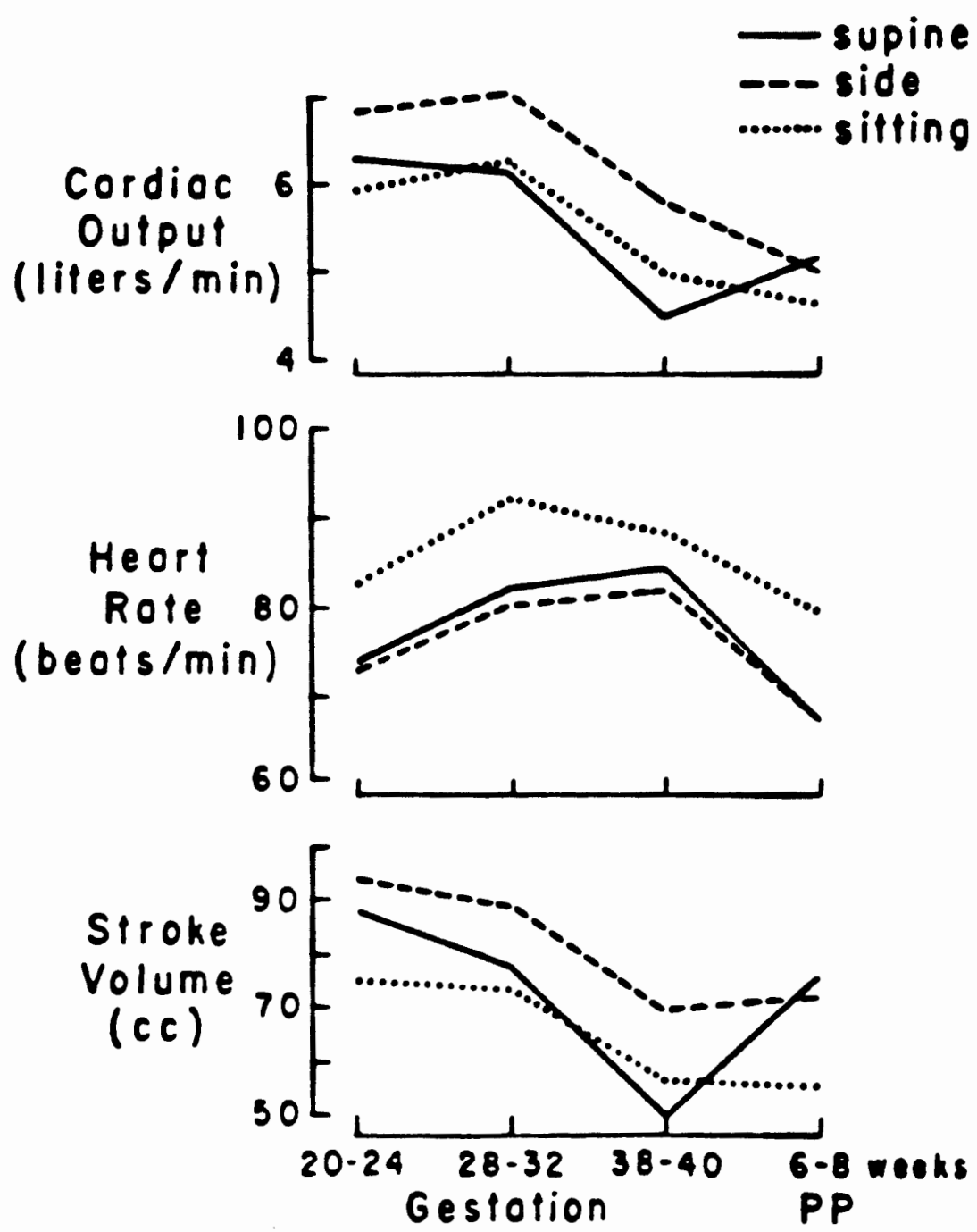


left ventricular function $(47,54,88)$. Rubler $\epsilon t a z .(71)$ and Burg Et al. (9) both used systolic time interval measurements to determine the functional status of the left ventricle during pregnancy but came to conflicting results. Rubler et al. reported that the isovolumic contraction period during the third trimester was significantly shorter than at postpartum, and concluded that the left ventricular contractility was enhanced during pregnancy, while Burg et al. reported a shortened left ventricular ejection time during the third trimester with a prolonged pre-ejection period suggesting an impaired left ventricular performance. A recent serial echocardiographic study (35) has shown that left ventricular performance remains unchanged during pregnancy and suggests that the different calculations of systolic time intervals during gestation are influenced by position. However, since these methods are sensitive to changes in both preload and afterload (44), definitive studies of ventricular function during pregnancy remain to be completed.

Changes in afterload during pregnancy are also difficult to evaluate. Sonnenblick (78) evaluated the role of aortic blood pressure as a determinant of left ventricular performance in the intact cat heart, then compared the effects of afterloading on work performed by isotonically contracting isolated cat papillary muscle. In the papillary muscle at any one length and state of contractility, work was determined by the afterload to which the muscle was exposed. In the intact cat heart, at any given filling pressure, work performance was largely dependent on blood pressure (afterload).

Afterload in the intact heart is probably best approximated by 
wall stress. In an isotonically contracting ventricle, wall stress has been shown to be the major determinant of ventricular performance at a constant preload (11). In the intact circulation though, stress in the ventricular wall is related to the external constraints on ventricular ejection and these relations are complicated by the shape of the contracting ventricle and by the physical properties of the vascular system into which it pumps blood. Milnor (55) described arterial input impedance as a measure of afterload that expresses all of the external factors that oppose ventricular ejection of blood making aortic impedance an important determinant of wall stress. A major component of aortic impedance is systemic vascular resistance (55). It has been observed that peripheral vascular resistance decreases during pregnancy (4) and that this change is manifested by a lowering of systemic arterial pressure in spite of an increased cardiac output $(35,43)$.

Echocardiographic studies during pregnancy and postpartum $(35,38,71)$ found an increase in the end-diastolic dimension without an increase in septal or left ventricular posterior wall thickness. Calculated left ventricular mass increased slightly throughout gestation (35) suggesting that only a mild degree of left ventricular hypertrophy occurs during pregnancy. These observations of left ventricular enlargement have been observed in an animal model in which filling pressure was maintained at a constant level $(28,60)$. They examined the passive in vitro pressure-volume relations of the left ventricle in end-gestation pregnant and nonpregnant guinea pigs. Figure 2 demonstrates that the in vitro pressure-volume relationships of the left ventricles of pregnant animals were shifted to the right of coritrols. At $10 \mathrm{~mm} \mathrm{Hg}$ distending 


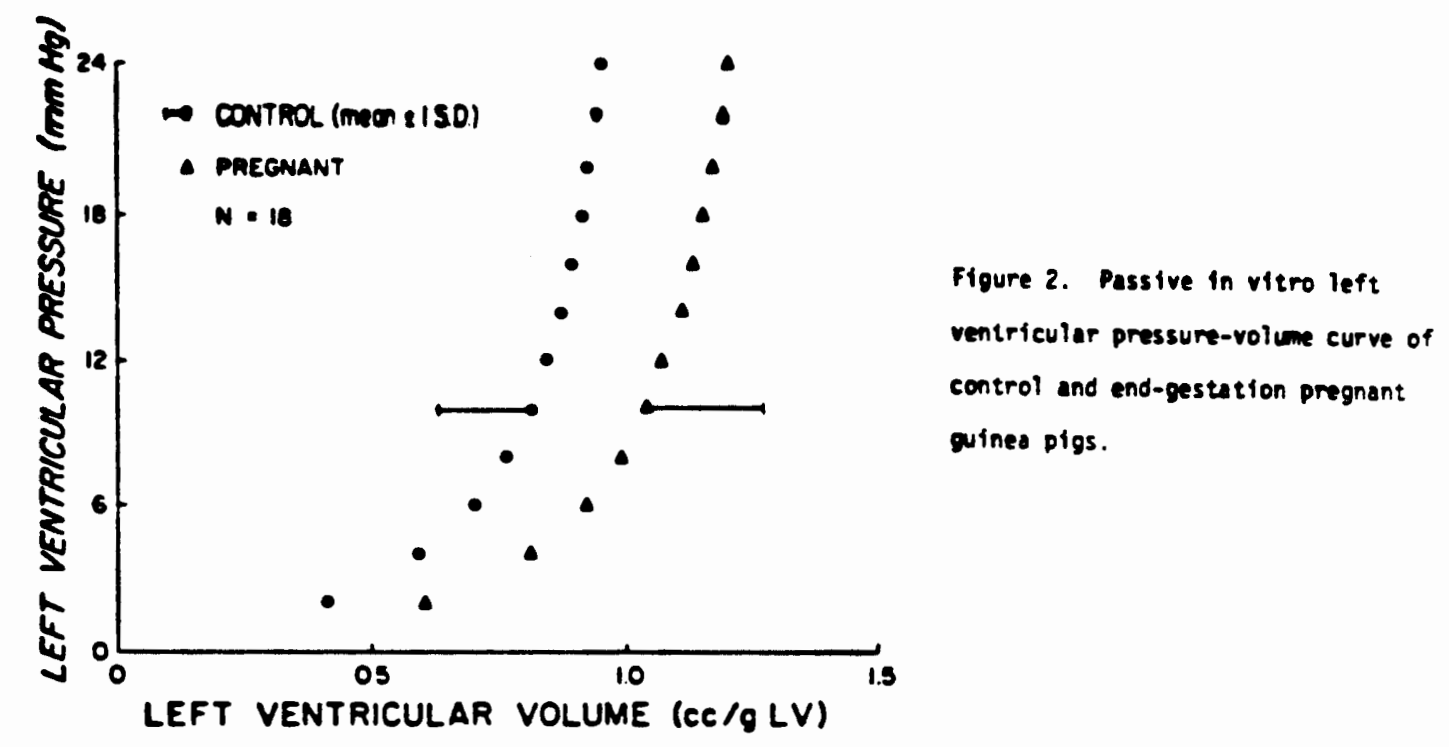

pressure, left ventricular volume was increased $16 \%$ in the pregnant animals. There was no difference between the left ventricular weights of the pregnant and nonpregnant guinea pigs and the calculated radius: wall thickness ratio was increased in the pregnant animals. These findings suggest that ventricular enlargement without hypertrophy occurs in guinea pig pregnancy.

This fourth determinant of stroke volume, ventricular enlargement, is usually utilized for long-term cardiovascular adaptations (70). Ventricular radius and wall thickness are the primary geometric determinants of wall stress (Law of Laplace). In pregnancy the radius to wall thickness ratio is increased, potentially increasing wall stress and raising the possibility that during gestation the left ventricle may be more susceptible to increases in afterload. These geometric changes may be offset by the previously mentioned reduction of vascular resistance and systemic pressure.

The mechanism for the left ventricular enlargement during 
pregnancy is not adequately explained. In 1938, Burwell (14) presented the hypothesis that the placenta acted as a modified arteriovenous ( $A-V)$ fistula which may account for the circulating changes seen during pregnancy. The hemodynamic changes seen in pregnancy (increased cardiac output, increased heart rate, a narrowed $\mathrm{A}-\mathrm{V}_{2}$ difference, and a widened pulse pressure) are consistent with features seen in an A-V fistula (75). Burwell went on to describe the changes in placental circulation prior to term that may be responsible for a reduction in the A-V shunt effect which may in turn account for the return of cardiac output and $A-V$ oxygen difference towards normal just before delivery. Recent studies have shown that increased cardiac output in human pregnancy occurs by the first trimester $(35,83)$ but there is not a significant increase in uterine blood flow at that time to account for the $A-V$ shunt effect $(3,53)$. When comparing the ventricular enlargement of pregnancy to other physiologic or pathophysiologic states associated with ventricular enlargement, obvious differences emerge (Table I).

Tabie 1. Sumary of cardiovascular alzerations seen during pregnancy, . chroric volume overloading (experimerital A-V fistuia) and physical troining.

\begin{tabular}{|c|c|c|c|c|c|c|}
\hline & \multicolumn{6}{|c|}{ Cardiovascular Parameter } \\
\hline & CO & SV & LVEDF & IVEDC & lvw: & $R: h$ \\
\hline Pregnansy & 4 & 4 & $=$ & 4 & $=$ & 4 \\
\hline Chroric volume overload & 4 & 4 & 4 & 4 & $?$ & $?$ \\
\hline Physical training & 4 & 4 & $=$ & 4 & 4 & + \\
\hline
\end{tabular}

$C O=$ cardiac oulDut; $S V=$ stroke volume; LVEOF = left vertficuiar end-diastolic pressure: IVED? - left ventricular end-diastolic dimersior.: IVaT = left ventriculor wall thickness; $R: h$ = rasius: wall inickness ratio 
Ross and McCullagh investigated the mechanisms of adaptation to chronic ventricular volume overload $(50,70)$. The volume overload is produced by the surgical creation of an arteriovenous fistula between the aorta and inferior vena cava. The left-to-right shunt places a large volume overload on the left ventricle. Left ventricular dimensions were measured by cineradiography using radiopaque subendocardial beads and left ventricular end-diastolic pressure (LVEDP) was measured with an in-dwelling catheter. A progressive increase in LVEDP, stroke volume and left ventricular end-diastolic volume was observed over an eight- to ten-week period. No significant depression of contractility, as assessed by mean velocity of wall shortening, was noted during this period despite a markedly elevated LVEDP and left ventricular hypertrophy. Despite a shift of the left ventricular end-diastolic pressurevolume curve to the right, left ventricular compliance was decreased. The degree of left ventricular enlargement is comparable in both arteriovenous fistula and pregnancy, an $11 \%$ and a $10 \%$ increase in enddiastolic dimensions, respectively. In contrast, left ventricular enlargement in pregnancy is not associated with an increased filling pressure (4), suggesting that ventricular compliance is increased or geometric remodeling occurs during pregnancy.

Echocardiographic studies of the athlete's heart reveal changes even less similar to the left ventricle during pregnancy $(18,59,69)$. Left ventricular end-diastolic volume is increased, but left ventricular mass increases markedly with training which decreases the radius:wall thickness ratio. A concurrent increase in right ventricular dimension and mass was also observed. Neither of these changes seen in trained 
athletes, reduced radius:wall thickness ratio or right ventricular hypertrophy, are consistent with alterations observed during pregnancy.

Estrogen and progesterone, hormones which undergo major alterations during pregnancy, have been shown to exert substantial alterations in cardiovascular hemodynamics. In 1955, Brehm and Kinderling hypothesized that cardiac output was regulated by peripheral resistance to blood flow. The authors felt that the fundamental cause of the alterations in cardiac output during pregnancy was due to a variation of maternal hormones. Ueland and Parer investigated the effects of exogenous administration of estrogen on the cardiovascular system of the ewe (84). They observed an increase in cardiac output and heart rate with a fall in mean arterial pressure and peripheral resistance. The changes seen during estrogen administration were similar to those seen in pregnant ewes (52). Several studies have been performed on women taking oral ccintraceptives $(39,85,86)$. Hemodynamic changes were monitored serially in women prior to, during and after administration of a combined estrogen/progesterone contraceptive. Significant increases occurred in cardiac output, blood volume, stroke volume and blood pressure in as early as three months (85). Lehtovirta also administered estrogen and progesterone separately and found similar cardiovascular changes in the women receiving the estrogen but not in the progesteronetreated patients (39). This indicates that the hemodynamic alterations observed during combined estrogen/progesterone oral contraceptive treatment are caused by estrogens. It has also been shown that combined estrogen/progesterone oral contraceptive treatment increased peripheral venous distensibility which reduced the linear velocity of venous blood 
flow by increasing the venous volume $(26,40)$. A recent study has confirmed the changes seen during oral contraceptive treatment but showed that venous compliance is also modified by progesterone $(20)$. They also demonstrated that pregnant women differed from women on oral contraceptives in regard to peripheral circulation. During pregnancy there is a marked increase in blood flow with secondary vasodilation.

Studies in our laboratory (31) were undertaken to further investigate the role of hormones on the cardiovascular alterations of pregnancy. Guinea pigs were dosed with estrogen, progesterone, and estrogen and progesterone via subcutaneous silastic implants to achieve hormone levels comparable to those seen during pregnancy. Hemodynamic and left ventricular pressure-volume relations were examined after 28 days of hormone treatment. Cardiac output increased $22 \%$ in the estrogen-dosed animals with no concomitant increase in uterine blood flow. Cardiac output remained unchanged in the progesterone and estrogen and progesterone-dosed animals. There was also a $31 \%$ increase in stroke volume noted in the estrogen-dosed group as well as a $13 \%$ increase in blood volume. The left ventricular weights were not significantly different between the control and estrogen-dosed guinea pigs, however, the left ventricular pressure-volume relationship of the estrogen-treated animals were shifted to the right with a $16 \%$ increase in ventricular volume (figure 3). Ventricular compliance was not different between the estrogen-treated group and the control animals suggesting a geometric remodeling of the left ventricle rather than a change in muscle elasticity.

To investigate whether estrogen acts on the peripheral or central 
Figure 3. The in vitro left ventricular (LV) pressurevolume curve is significantly shifted to the right in the estrogen-treated animals. At $10 \mathrm{~mm} \mathrm{Hg}$ distending pressure, the LV volume was increased by $18 \%$. 

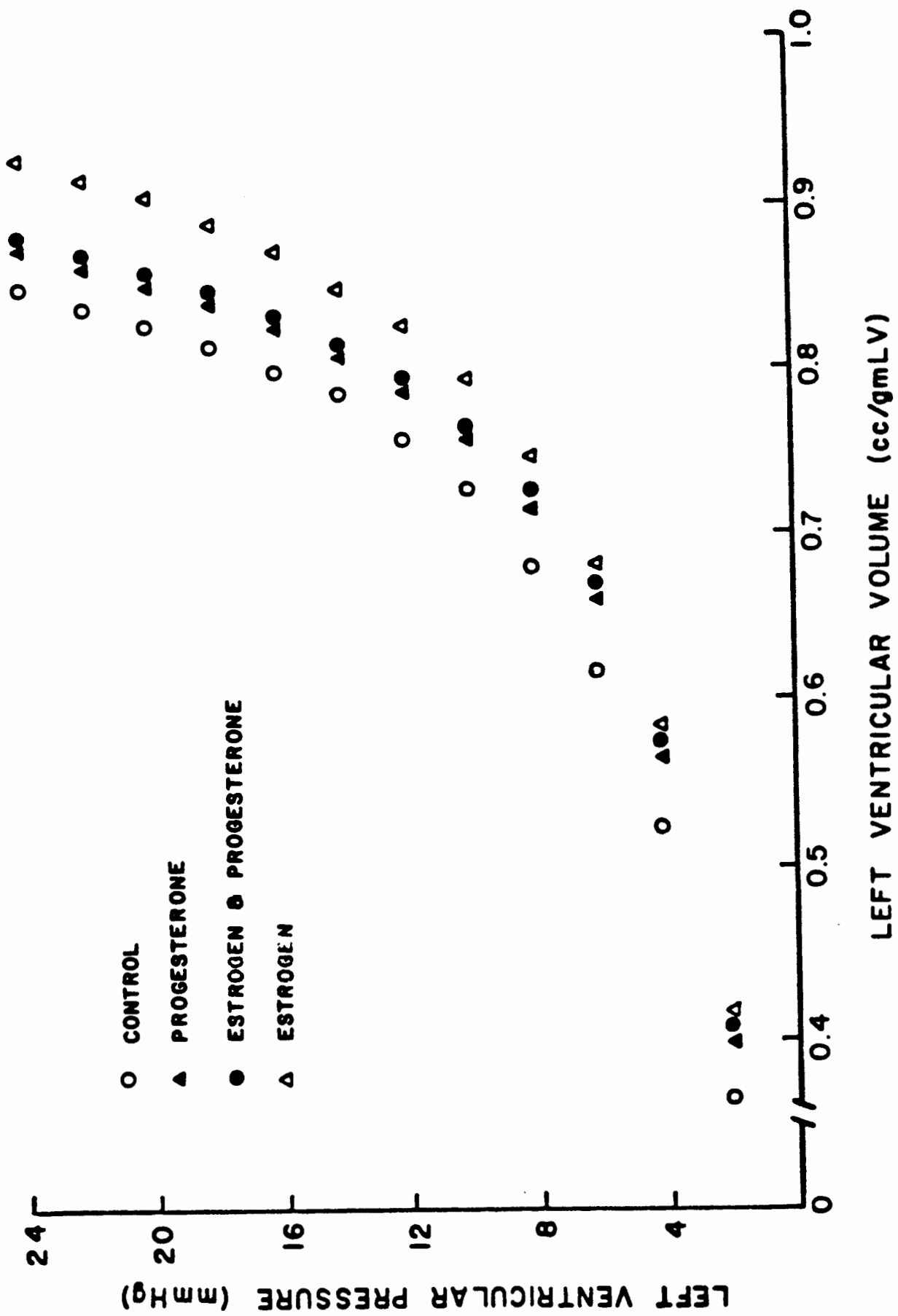
cardiovascular system, several studies have examined the location of steroid receptors $(46,48,49,82)$. These studies all indicate that the heart and major arteries of several mammalian species contain androgen and estrogen receptors in distinctive patterns of distribution among muscle and connective tissue cells suggesting that the central cardiovascular system may be a target organ for these hormones. 


\section{METHODS}

\section{EXPERIMENTAL ANIMAL SELECTION}

The guinea pig was chosen as the experimental animal model to study maternal cardiovascular adaptations to pregnancy for several reasons. Guinea pigs assume an unusually large reproductive burden as evidenced by the large weight of its fetuses which is approximately $30 \%$ of maternal weight by the end of gestation. In addition to a relatively long gestation period of 68 days which allows for long-term cardiovascular adaptations, the hormonal profile of the guinea pig during pregnancy is qualitatively more similar than other animals to humans, as both have an early rise in circulating progesterone levels and a latter rise in estrogen (see figure 4). A previous study (60) has also demonstrated that cardiac enlargement occurs during pregnancy in the guinea pig. Finally, the guinea pig is small, easily maintained and relatively inexpensive when compared to larger animals, yet they are large enough to allow adequate instrumentation. These combined characteristics make the guinea pig an attractive animal in which to study perinatal physiology.

\section{ANIMAL PREPARATION AND INSTRUMENTATION}

All animals used in this study were virgin female guinea pigs (Duncan-Hartley strain) between 500 and 800 grams in body weight. The animals were housed in the Oregon Health Sciences University's Department of Animal Care facilities in groups of three or four and the 
Figure 4. Circulating hormone levels during pregnancy in five species. The solid line indicates progesterone $(P)$ and the dashed line estrogen $(0)$. (91)
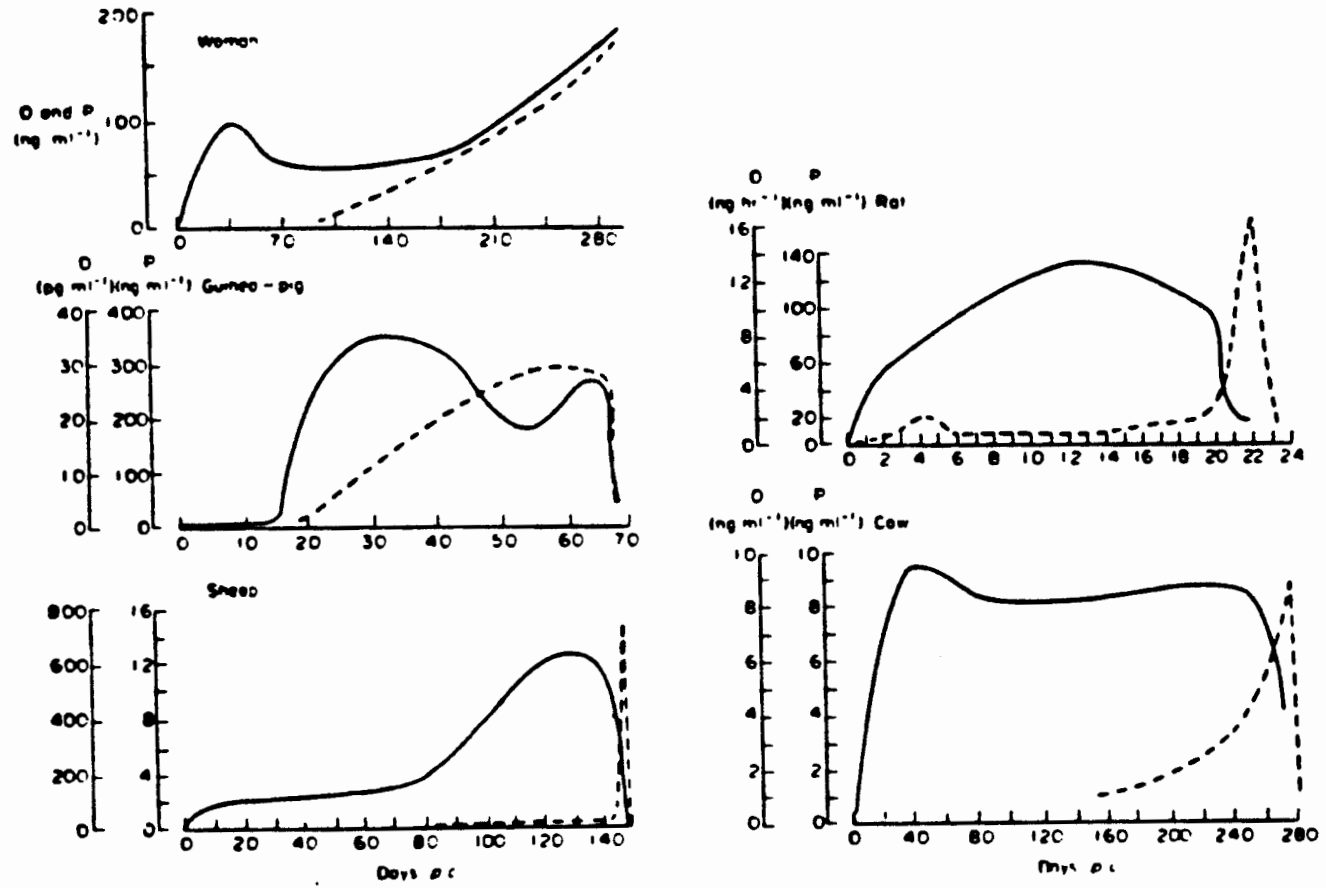
temperature maintained at $21^{\circ} \mathrm{C}$. A twelve-hour light cycle was employed and the guinea pigs had free access to food and water at all times.

In order to study the cardiovascular changes at various stages of pregnancy, the animals were studied at 20, 40, and 60 days of gestation. The animals were received over a five-month period, ear-tagged for identification and prospectively weight-matched and randomly assigned to one of the following study groups:

CONTROL (nonpregnant)

PREGNANT (Day 20 of gestation)

PREGNANT (Day 40 of gestation)

PREGNANT (Day 60 of gestation)

The sows assigned to the pregnant groups were monitored daily to determine when the animals were in estrus as detected by vaginal opening. At that time, the sows were caged with a boar for 48 hours to provide a dated pregnancy. The sows' weights were recorded on Day 0 of gestation for purposes of weight-matching. Pregnancy was verified by palpation at 16-20 days of gestation.

On the day of the study, each animal was given an intramuscular injection of $25 \mathrm{mg}$ Ketamine and $0.15 \mathrm{mg}$ xylazine to provide a surgical level of anesthesia for instrumentation. A ventral neck incision was made and the left carotid artery and jugular vein were dissected free and isolated followed by an incision in the right groin to isolate the superficial saphenous artery. Polyvinyl catheters $(0.90 \mathrm{~mm}$ 0.D., $0.50 \mathrm{~mm}$ I.D.) were used for all catheterization. The superficial saphenous artery catheter was advanced to five $\mathrm{cm}$ which extended the tip of the catheter into the abdominal aorta just below the renal arteries. This catheter measured systemic arterial pressure and served as an arterial 
reference catheter for cardiac output measurements. A right atrial catheter was placed via the left jugular vein. The left ventricular catheter was then introduced through the left carotid artery. The catheter was directed into the ascending aorta with the aid of a stylet and passed retrograde across the aortic valve into the left ventricle. Following verification of catheter position by pressure monitoring, the catheters were filled with a dilute heparin solution and capped. All three catheters were tunneled subcutaneously to the back of the neck where they were secured until the animal was studied. All animals were allowed free access to food and water during the recovery period.

STUDY PROTOCOL

In Vivo Pressure Measurements

Between three and four hours after recovery from anesthesia, the animals were $\mathrm{placed}$ in a cage providing limited restraint and allowed to acclimate for a period of 30-45 minutes. Blood glucose levels were determined immediately prior to the study. Right atrial, aortic and left ventricular pressures were then simultaneously recorded with Statham P-23Db transducers zeroed at midchest on a Beckman R-611 dynograph recorder.

Figure 5 demonstrates examples of pressures which were recorded during the study. Heart rate was obtained from the left ventricular pulse tracing and the respiratory rate was obtained from the right atrial wave form which measured changes in the intrathoracic pressure occurring with respiration. 
Figure 5. Strip chart recordings (non-simultaneous) of Aortic (AO), left ventricular (LV), and right atrial (RA) pressures at the time of study. The a wave and left ventricular end-diastolic pressure (LVEDP) are easily recognized on the $L V$ tracing. Changes in intrathorasic pressure that occured with respiration can be seen on the RA tracing. $\overline{A O}$ and $\overline{R A}$ stand for mean pressures. 


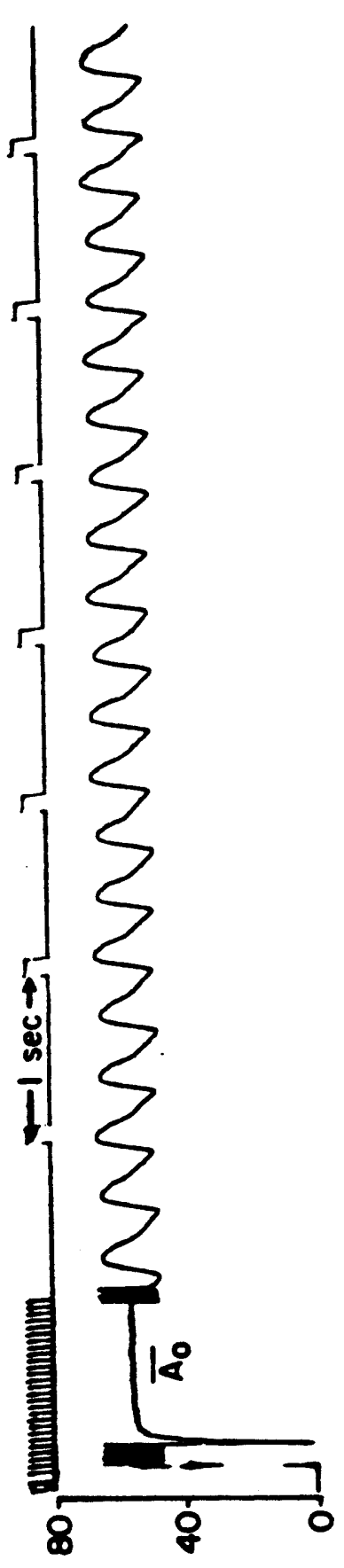
anssody ov

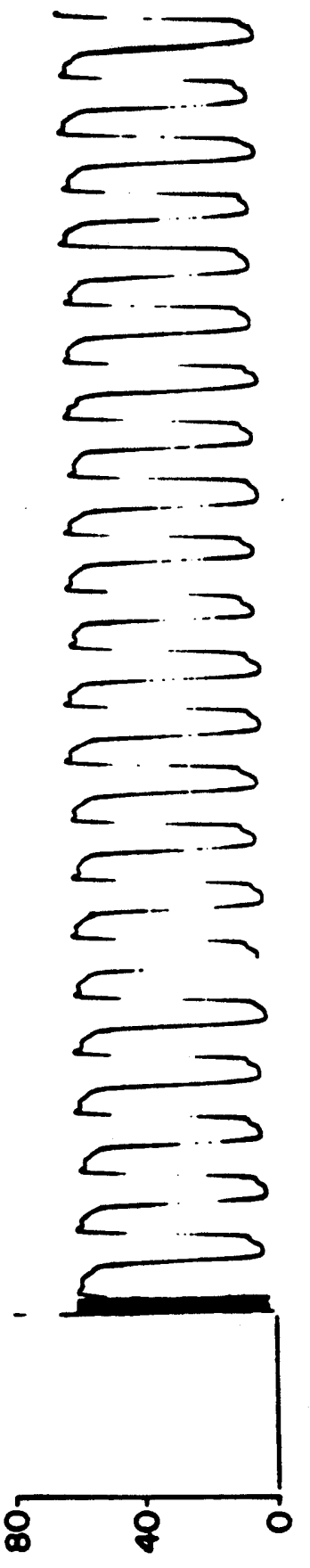

anssadd 17

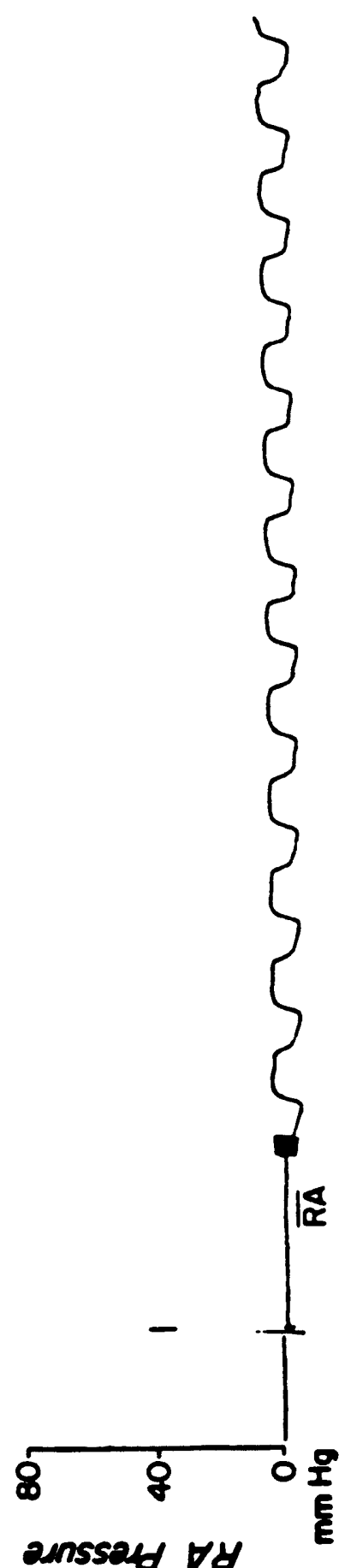


Cardiac Output and Organ Blood Flows

Cardiac output and regional distribution of blood flows were then obtained by a modified standard indicator dilution technique using 15 micron radioactive microspheres which are trapped on their first pass through the circulation in the arteriolar or capillary vascular system $(27,45)$.

When using microspheres, several important factors were considered in order to insure accurate measurements of regional flow (8). First, the microspheres must be evenly mixed and evenly distributed to all major arteries leaving the injection site so that the spheres evenly reach all branching sites. To obtain a distribution of spheres that is similar to the flow of blood, the spheres used have a relative density of $1.3 \mathrm{gm} / \mathrm{ml}$ which is similar to the density of blood and were passed through a 27-gauge needle and mixed with Dextran and saline immediately prior to injection to disperse any microsphere aggregates. The spheres were injected into the left ventricle to insure mixing throughout the blood prior to the first major arterial branching.

It is also essential that all microspheres are trapped in the microcirculation and that a significant number not bypass any organs of interest. Since the diameter of capillaries and arteriovenous anastomoses may vary considerably among organs, the size of the microsphere selected must assure that injected microspheres do not pass through the organ and into the venous system $(45,61,74)$. For this study, 15 micron microspheres were selected as they seem to balance the need for distribution of microspheres similar to red blood cells with the absence of significant non-entrapment. 
To obtain a measurement, the arterial reference catheter (abdominal aortic catheter) was attached via a blunt needle to a previously weighed triton heparinized $5 \mathrm{ml}$ glass syringe. The syringe was placed in a Harvard withdrawal pump set at a constant withdrawal rate of .68 $\mathrm{ml} / \mathrm{min}$. The withdrawal was started, and a sample of approximately 1 million 15 micron single-labeled radioactive microspheres was injected into the left ventricle over a period of 30 seconds, followed by a slow two $\mathrm{ml}$ flush of normal saline to rinse the catheter of all microspheres. The withdrawal was continued for three minutes. The syringe was then reweighed in order to access accuracy of the blood withdrawal. The triton hemolyzed blood was then carefully transferred into a counting vial and the syringe rinsed repeatedly with distilled water to wash out any microspheres and residual blood.

The kidneys, lungs, and uterus and contents were dissected free and desiccated in alcohol. The remaining carcass was ashed to reduce the mass of tissue and to allow for even distribution of microspheres in the ashed aliquots.

The: radioactivity of the reference sample, organs, and eight we11mixed weighed aliquots of ashed carcass were then determined using a 512-channel pulse-height analyzer (Packard Autogamma Counter). Organ and carcass blood flow was calculated by the following formulas:

$\frac{\operatorname{organ}(\mathrm{cpm})}{\text { reference sample }(\mathrm{cpm})} \times$ BWR $=$ organ blood flow $(\mathrm{ml} / \mathrm{min})$ $\frac{\text { carcass al iquots }(\mathrm{cpm})}{\text { reference sample }(\mathrm{cpm})} \times$ BWR $\times$ TAW $=$ carcass blood flow $(\mathrm{ml} / \mathrm{min})$ AAW

$\mathrm{cpm}=$ counts per minute

$\mathrm{BWR}=$ blood withdrawal rate 
AAW $=$ al iquot ash weight

TAW = total carcass ash weight

To determine cardiac output, all organ and carcass blood flows were added together giving total cardiac output.

The left and right kidneys were counted separately to serve as an internal check of the adequacy of microsphere mixing. The lungs were counted to ensure to adequacy of capillary entrapment of the microspheres.

\section{Blood Gas Analysis}

Following microsphere injection and reference sample collection, a one $\mathrm{ml}$ sample of heparinized arterial blood was taken from the aortic catheter. $\mathrm{pH}, \mathrm{pCO}_{2}$, and $\mathrm{pO}_{2}$ were measured with a Radiometer BMS Mark 3 Micro Blood Gas Analyzer calibrated at $39^{\circ} \mathrm{C}$. Hematocrit was determined from packed cell volume after five minutes of centrifugation.

Hormone Analysis

An additional one $\mathrm{ml}$ sample was obtained for steroid hormone analysis. The serum was extracted and stored at $-20^{\circ} \mathrm{C}$ until steroid analysis was performed. Estradiol $\left(E_{2}\right)$, estrone $\left(E_{1}\right)$ and progesterone $\left(P^{4}\right)$ were measured by a radioimmunoassay technique $(67,68)$. An aliquot of the serum sample was placed in a small tube with an equal volume of distilled water and then mixed with four to six $\mathrm{ml}$ of distilled ether. The mixture was centrifuged and the aqueous phase quick frozen by immersion into a methanol/dry ice bath and the ether extract was removed by decanting while the aqueous phase was kept frozen. The extracts were dried and further concentrated with successive washes of $2 \%$ ethanol ether. 
A column was prepared of Sephadex $\mathrm{LH}-20$ with a Hexane:Benzene: Methanol (62:20:13) solvent system to separate the neutral steroids from the estrogens and progesterone. The samples were applied to the columns and allowed to flow into the Sephadex bed before adding the eluting solvent. $E_{1}, E_{2}$ and $p^{4}$ fractions were obtained by adding solvent and collecting the particular fractions. Standard curves were prepared by placing 8 known concentrations of $E_{1}, E_{2}$ and $p^{4}$ into culture tubes in duplicate with several blank tubes for each standard curve. Appropriate antibodies and tritium-labeled solution were added to the corresponding standard curve, sample, and blank tubes and then placed on ice overnight. Dextran-coated charcoal solution was next added to the tubes for 15 minutes, the tubes centrifuged and the supernatant decanted into scintillation vials containing a detergent solution. Standard curves were constructed and the amount of hormone in the plasma was interpolated from the curve. Corrections for blanks were made and the data expressed in either picograms $/ \mathrm{ml}(\mathrm{pg} / \mathrm{ml})$ or nanograms $/ \mathrm{ml}(\mathrm{ng} / \mathrm{ml})$ of serum. This method is sensitive enough to detect as little as two $\mathrm{pg} / \mathrm{ml}$ of estrogen or progesterone (68).

\section{Blood Volume Measurements}

Blood volume (BV) was measured by standard indicator techniques employing Evans blue dye $(T-1824)$ as described by Wang (87). A measured dose of Evans blue dye was infused into the left ventricular catheter for optimal mixing and was rinsed immediately with two $\mathrm{ml}$ of saline to insure that all of the dye was delivered to the circulatory system. The dye was allowed to circulate for five minutes and then a one $\mathrm{ml}$ blood 
sample was obtained from the aortic catheter (37). The plasma from the sample was removed by centrifugation and the dye concentration was measured at $620 \mathrm{~nm}$ with a spectrophotometer zeroed with a blank plasma reference from the same animal. The plasma volume (PV) was then calculated from a known standard curve. This value combined with hematocrit, allows the calculation of blood volume by the following equation.

$$
\operatorname{BV}(\mathrm{ml})=\frac{P V(\mathrm{ml}) \times 100}{100-\operatorname{Hct}(\%)}
$$

\section{In Vitro Pressure-Volume Curves}

After hemodynamic data was obtained, the animals were anesthetized with an I.V. injection of a short-acting barbiturate followed by a one $\mathrm{ml}$ injection of saturated potassium chloride to produce diastolic cardiac arrest. The chest was rapidly opened, and the heart dissected free and removed. The right ventricular outflow tract was opened widely and the right ventricular free wall and papillary muscles were dissected from the septum. The incision was then extended across the atrialventricular groove arid right atrium trimmed back to the interatrial septum. A sriugly-fitting double lumen grooved plug as seen in figure 6 was

Figure 6. Apparatus used to isolate left ventricle during pressure-volume measurements.

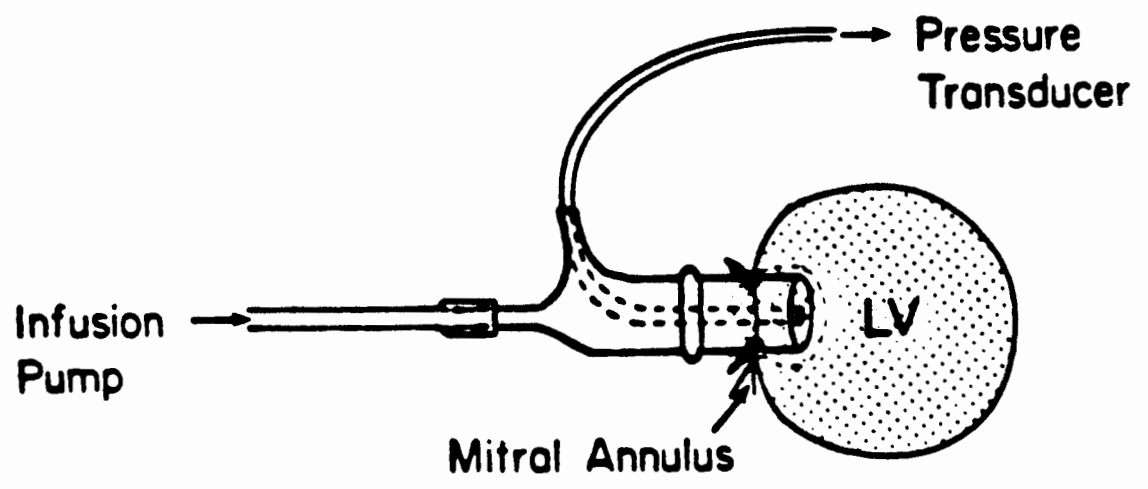


inserted into the mitral annulus through a hole in the left atrial appendage and secured in place by ligatures which course in the $A-V$ groove, across the aortic valve and around the interatrial septum. This procedure effectively isolates the left ventricle. The ventricle was then flushed with room temperature saline and suspended in a shallow dish with room temperature saline. The inner lumen of the cannula was connected to a Statham P-23Db transducer zeroed at mid-ventricular level and the outer lumen connected to a stopcock manifold and a Harvard constant infusion syringe pump filled with room temperature saline. The ventricle was manually emptied to create a negative pressure which was taken as zero volume and the intraventricular pressure was continuously recorded during volume infusion. The ventricle was filled over a fiveto ten-second period to minimize stress relaxation and was only filled to a pressure of $25 \mathrm{~mm} \mathrm{Hg}$ to avoid stretching. All fluid was then withdrawn and the process repeated until at least three reproducible pressure-volume curves were obtained. Our laboratory has not noted rigor, as evidenced by a leftward shift in the pressure-volume curve, in less than 45 minutes. Measurements in this study were restricted to less than 20 minutes from time of anesthesia. The stability of diastolic pressure-volume relations in isolated arrested ischemic ventricles has been confirmed in murine and canine hearts for 30 and 60 minutes, respectively $(23,58)$.

After satisfactory recordings were obtained, each ventricle was emptied and tested for leaks by the completeness of recovery of fluid injected into the ventricle to a pressure of $25 \mathrm{~mm} \mathrm{Hg}$. No leaks were observed. The heart was then disconnected from the plug. The incision 
of the atrioventricular groove was then completed, removing the right and left atrium from the left ventricle. The aorta was then severed at the aortic valve and the left ventricle was opened from the aortic annulus to the apex, blotted and weighed.

Pressure-time recordings during infusion were converted to pressure-volume curves utilizing the known infusion rate. The Harvard syringe pump was calibrated after each experiment by duplicate 60-second infusions into a graduated cylinder. The mean of three pressure-volume curves during infusions was obtained for each left ventricle by averaging pressure at $0.05 \mathrm{ml}$ increments of volume. The volume of each even value of pressure was obtained for analysis by interpolation from the pressure-volume curve over a range of intraventricular pressures from 2-24 mm $\mathrm{Hg}$.

In order to analyze any significant differences between these pressure-volume curves, linear transformations were performed on the data. As pressure increases exponentially with volume, stiffness constants $K_{1}$ and $K_{2}$ were calculated by fitting one exponential function of the form $P=b e^{k v}$ to the data from the low pressure range $(2$ to $20 \mathrm{~mm}$ $\mathrm{Hg}$ ) and a second exponential to the upper pressure range (12 to $24 \mathrm{~mm}$ $\mathrm{Hg})(21)$. Left ventricular chamber stiffness, derived as $d P / d V=K P$, and ventricular volumes were then compared from their exponential functions. Ventricular dimensions, wall stress, and stress-elastic modulus relationships were determined by using a thin-walled spherical model (34). The validity of this model in providing reliable calculations will be discussed later. The pressure-volume curves were approximated by a polynomial (fourth or rifth order) and $\mathrm{dP} / \mathrm{dV}$ determined by 
differentiation. Ventricular radius and wall thickness were calculated from instantaneous volume and the mass of the ventricle (Equations 1 and 2).

1. $V=(4 / 3) \pi(r-h / 2)^{2}$

2. $\left.h=w / 4 \pi r^{2} \rho\right)$

Wall stress $(\sigma)$ was determined from Equation 3,
3. $\sigma=\frac{\mathrm{Pr}}{2 h}$

and elastic modulus from Equation 4 , assuming $h / 2$ is small compared to $r$ and that $V=4 / 3 \pi r^{3}$.

$$
\begin{aligned}
& \text { 4. } E=3 \sigma(V / P) \mathrm{dP} / \mathrm{dV}+1 \\
& P=\text { ventricular pressure } \\
& V=\text { ventricular volume } \\
& r=\text { mean radius of ventricle } \\
& h=\text { wall thickness } \\
& W=\text { ventricular weight } \\
& \rho=\text { density of ventricle }\left(1.05 \mathrm{~g} \cdot \mathrm{ml}^{-1}\right) \\
& \sigma=\text { wall stress } \\
& E=\text { elastic modulus }
\end{aligned}
$$

By simultaneous inspection of the pressure-volume relationship, Equation 3 and the first order differentiation of $P$ with respect to $V$ for the polynomial, the elastic modulus was calculated at values of wall stress from 4-24 mm Hg utilizing a Data General computer.

\section{Autopsy Data}

After pressure-volume curves were obtained, the left and right kidneys, lungs, and the uterus and contents were removed from each animal and carefully weighed and the catheter positions were verified. In the pregnant animals, each separate fetus and placenta was removed 
from the uterus and its position and weight were recorded. All organs and reproductive products were dried in alcohol and the radioactivity measured as described previously.

\section{Effects of Anesthesia}

In order to ascertain the completeness of recovery from anesthesia in this study, eight additional guinea pigs were instrumented as previously described with the same anesthesia mixture $(25 \mathrm{mg}$ Ketamine, $0.15 \mathrm{mg}$ xylazine). The animals were allowed to recover for four to six days with free access to food and water. After the recovery period, they were weighed and placed in a limited restraint cage and allowed to acclimate for 30-45 minutes. Pressures were then obtained followed by an arterial blood gas sample and cardiac output determination with radioactive microspheres. The animals were then anesthetized with the identical anesthesia mixture used during the pregnancy study and serial pressures were taken every 30 minutes. Three to four hours after recovery from the anesthesia (as evidenced by upright posture and mobility) pressures, arterial blood gases, and cardiac outputs were again measured. The animal remained in the limited restraint cage throughout the recovery and measurement periods. The animals were then sacrificed and the kidneys were removed and counted separately and the carcass asted. Cardiac output was determined as previously described.

\section{Data Analysis}

The significance of differences between means of hemodynamic measurements was determined by analys is of variance. The significance of differences between pressure-volume coordinates for the different 
study groups was determined by analysis of covariance for the linear relationships defined by pressure as a mono-exponential function of volume. The approximation of pressure-volume curves by polynomials was accomplished by computing $F$ values from the reduction of the sum of squares for successive Nth order polynomials. The Nth order polynomial with an $F$ value indicating a probability of difference of less than $5 \%$ was used (77). The ventricular dimensions derived from the thin-wall spherical model were compared by analysis of variance and the linear stress elastic modulus relationship by analysis of covariance. When an $F$ value indicated a significant difference $(P<0.05)$, a multiple comparisons test was performed (Scheffe test) to compare the differences between individual pairs of means (65). This test consists of computing an F statistic for each comparison using the following formula.

$$
F=\frac{\left(\bar{x}_{1}-x_{2}\right)^{2}}{M S_{e}\left(n_{1}+n_{2} / n_{1} n_{2}\right)}
$$

The mean square for error $\left(M S_{e}\right)$ comes from the ANOVA. The $F$ values obtained from the Scheffe test are then divided by the number of groups compared in the ANOVA minus one. This value is then compared to a critical value from a table to determine the probability of a difference. 


\section{RESULTS}

\section{ANIMAL WELL-BEING}

Control and pregnant groups were well-matched as evidenced by their similar bridy weights (shown in Table II) at the time of randomization into study groups. All of the pregnant animals gained weight during the study with a $70 \%$ increase in maternal weight occurring by 60 days of gestation. The individual organ weights are also shown on Table II. Fetal and uterine and placental weights were significantly increased during pregnancy $(p<0.001)$ as was expected with the greatest gain occurring during the last trimester of pregnancy. Kidney weights, wet lung weights and left ventricular weights were unchanged during pregnancy despite the increase in total maternal weight.

Arterial blood gases obtained at the end of the study are shown in Table III. These values are similar to those previously reported in control animals (6). To further access the recovery of the animals from anesthesia, an additional set of eight animals were anesthetized with a similar anesthesia mixture (25 $\mathrm{mg}$ Ketamine and $0.15 \mathrm{mg}$ Xylazine). Hemodynamic data during and after recovery from anesthesia are reported in Table IV and Figure 7. Cardiac output, heart rate and mean arterial pressure were not significantly different between the control values before anesthesia and four hours after recovery. These data further indicate that the animals had completely recovered from anesthesia. 
Table II. Body and organ weights of control and pregnant animals.

\begin{tabular}{|c|c|c|c|c|}
\hline & \multirow[b]{2}{*}{$\begin{array}{c}\text { CONTROL } \\
(n=14)\end{array}$} & \multicolumn{3}{|c|}{ PREGNANT GROUPS } \\
\hline & & $\begin{array}{l}20-D A Y \\
(n=11)\end{array}$ & $\begin{array}{l}\text { 40-DAY } \\
(n=13)\end{array}$ & $\begin{array}{l}60-D A Y \\
(n=13)\end{array}$ \\
\hline Starting Mass & $620 \pm 91$ & $629 \pm 88$ & $595 \pm 71$ & $608 \pm 51$ \\
\hline Study Mass & $620 \pm 91$ & $720 \pm 90$ & $812 \pm 75$ & $1.033 \pm 67$ \\
\hline Right Kidney Mass & $2.30=.36$ & $2.45 \pm .31$ & $2.42 \pm .27$ & $2.64 \pm .33$ \\
\hline Left Kidney Mass & $2.35=.37$ & $2.60 \pm .34$ & $2.49 \pm .30$ & $2.52=.27$ \\
\hline Lung Wet Mass & $3.11=.46$ & $3.91 \pm .71$ & $3.64 \pm .36$ & $3.90=.82$ \\
\hline LV Mass & $1.16=.17$ & $1.19=.16$ & $1.17 \pm .10$ & $1.18=.13$ \\
\hline Uterus \& Contents & $1.2 \pm .3$ & $8.5 \pm 2.9 *$ & $88.2 \pm 24.4^{*}$ & $298.3 \pm 52.6 *$ \\
\hline Fetal Mass & 0 & $.8 \pm .4$ & $45.9 \pm 13.9 *$ & $250.9 \pm 47.8$ \\
\hline
\end{tabular}

Results are expressed as mean weight $(g m)=S . D$.

*:.001; control vs. pregnant group 
Table 1II. Arterial blood gases analysis of control and pregnant guinea pigs.

\begin{tabular}{|c|c|c|c|c|}
\hline & \multirow[b]{2}{*}{$\begin{array}{l}\text { CONTROL } \\
(n=14)\end{array}$} & \multicolumn{3}{|c|}{ PREGNANT GROUPS } \\
\hline & & $\begin{array}{l}20-D A Y \\
(n=11)\end{array}$ & $\begin{array}{l}40-D A Y \\
(n=13)\end{array}$ & $\begin{array}{l}\text { 60-DAY } \\
(n=13)\end{array}$ \\
\hline $\mathrm{P}_{2}$ (torr) & $81.7 \pm 8.0$ & $81.1 \pm 10.7$ & $83.5 \pm 7.4$ & $86.5 \pm 10.4$ \\
\hline $\mathrm{PCO}_{2}$ (torr) & $36.4 \pm 5.4$ & $32.6 \pm 3.9$ & $33.8 \pm 4.3$ & $34.4 \pm 4.5$ \\
\hline pH & $7.37 \pm .05$ & $7.39 \pm .03$ & $7.40 \pm .04$ & $7.40 \pm .04$ \\
\hline
\end{tabular}

Results are expressed as mean \pm S.D. 
Table IV. Anesthesia recovery data on eight additional guinea pigs.

\begin{tabular}{|c|c|c|}
\hline & $\begin{array}{c}\text { PRE- } \\
\text { ANESTHESIA } \\
(N=8)\end{array}$ & $\begin{array}{l}\text { POST- } \\
\text { ANESTHESIA } \\
(N=8)\end{array}$ \\
\hline Heart Rate & $304=41$ & $303=41$ \\
\hline$M_{i}=(m+4 g)$ & $68=7$ & $66 \pm 7$ \\
\hline Cardiac Output $(\mathrm{ml} / \mathrm{min} / \mathrm{kg})$ & $376 \pm 97$ & $413 \pm 131$ \\
\hline Stroke Volume (cc) & $0.9 E=0.18$ & $0.84=0.13$ \\
\hline $\mathrm{PO}_{2}$ (torr) & $72.4=4.1$ & $81.0=13.0$ \\
\hline $\mathrm{PCO}_{2}$ (torr) & $3 E .6=4 . \varepsilon$ & $34.1=3.0$ \\
\hline $\mathrm{pH}$ & $7.42=.04$ & $7.43=.023$ \\
\hline Respirator: rate & $104=35$ & $113=24$ \\
\hline
\end{tabular}

Results are expressed as mean = S.D. 
Figure 7. Hemodynamic data from anesthesia recovery showing that mean arterial pressure and heart rate both returned to control values within four hours. Results are expressed as mean \pm SEM. 

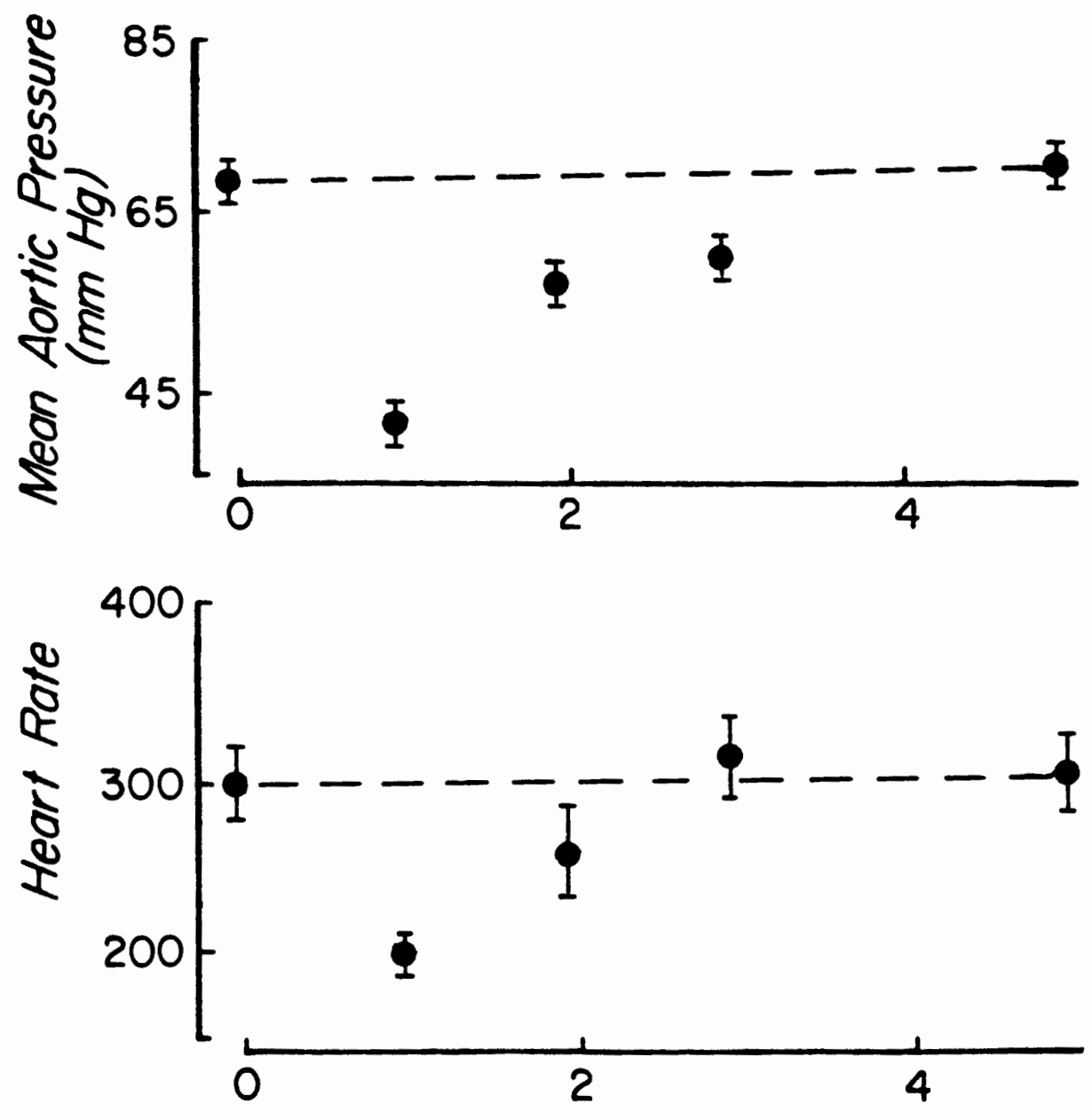

Hours Post Anesthesia 


\section{IN VIVO PRESSURE MEASUREMENTS}

Hemodynamic data from the control and pregnant guinea pigs are presented in Table $V$. There was no statistically significant difference in heart and respiratory rates, or aortic, right atrial or left ventricular end-diastolic pressures during pregnancy. Pulse pressure also remained constant throughout pregnancy.

\section{CARDIAC OUTPUT AND REGIONAL BLOOD FLOW}

Cardiac output and regional blood flow data are reported in Table VI. Total cardiac output was increased by $27 \%(p<0.05)$ as early as Day 20 of gestation. Although the cardiac output at Day 40 and Day 60 are not statistically elevated over nonpregnant control values, they appear to be gradually returning to pre-pregnant values from a high at 20 days. Uterine blood flow was not significantly increased until Day 40 of pregnancy. Between Day 40 and 60 uterine blood flow increased only $8 \%$ while uterus and content weight increased over $200 \%$ during the same period. Left ventricular blood flow remained unchanged during pregnancy while renal blood flow exhibited a $25 \%$ decrease $(p<0.05)$ at 40 days. Stroke volume was reported earlier in Table VI and was increased $25 \%$ at 20 days of pregnancy and remained elevated throughout the remainder of gestation.

\section{HORMONE DATA}

Estradiol, estrone and progesterone were measured at the end of the study in control and pregnant animals and the results are reported 
Table V. Hemodynamic data from control and pregnent guinea pigs.

\begin{tabular}{|c|c|c|c|c|}
\hline & \multirow[b]{2}{*}{$\begin{array}{l}\text { CONTROL } \\
(n=14)\end{array}$} & \multicolumn{3}{|c|}{ PREGNANT EROUPS } \\
\hline & & $\begin{array}{l}20-D A Y \\
(n=10)\end{array}$ & $\begin{array}{l}\text { 40-DAY } \\
(n=13)\end{array}$ & $\begin{array}{c}\text { 60-DAY } \\
(n=9)\end{array}$ \\
\hline Heart rate & $284=35$ & $289 \pm 17$ & $281 \pm 34$ & $259=35$ \\
\hline $\operatorname{MAP}(m \mathrm{mH} g)$ & $63 \pm 6$ & $61=5$ & $61 \pm 8$ & $62 \div 7$ \\
\hline Pulse pressure (mmg) & $27: 7$ & $25 \pm 5$ & $25: 6$ & $23: 6$ \\
\hline LVEDP $\left(\mathrm{mmH}_{3}\right)$ & $5=3$ & $5=3$ & $5 \pm 3$ & $7 \pm 4$ \\
\hline Mean RA pressure (mmHg) & $1=2$ & $0=1$ & $1=2$ & $1=1$ \\
\hline Respiratory rate & $95=33$ & $125=45$ & $108=22$ & $129=37$ \\
\hline Stroke volume & $0.73=.12$ & $0.91 \div .24^{*}$ & $0.91=.15^{*}$ & $0.96 \div .15 *$ \\
\hline
\end{tabular}

Results are expressed as mean $=S . D$.

$\because-05$; control vs. pregnant group.

MAP = mear orterial pressure; LVEDP = left ventricular end-diastolic pressure: $R A=$ right atriai. 
Table VI. Cardiac output and regional blood flows of control and pregnant animals.

\begin{tabular}{|c|c|c|c|c|}
\hline & \multirow[b]{2}{*}{$\begin{array}{c}\text { CONTROL } \\
(n=13)\end{array}$} & \multicolumn{3}{|c|}{ PREGNANT GROUPS } \\
\hline & & $\begin{array}{l}20-D A Y \\
(n=10)\end{array}$ & $\begin{array}{l}\text { 40-DAY } \\
(n=10)\end{array}$ & $\begin{array}{c}\text { 60-DAY } \\
(n=8)\end{array}$ \\
\hline Cardiac Output (m\}/min) & $206 \pm 25$ & $261 \pm 42 \star$ & $251 \pm 54$ & $241 \pm 34$ \\
\hline Lung Blood Flow (ml/min) & $7.8 \pm 4.7$ & $12.0 \pm 7.1$ & $16.7 \pm 5.6$ & $14.8 \pm 7.8$ \\
\hline LV Blood flow $(\mathrm{ml} / \mathrm{min})$ & $4.2 \pm 1.5$ & $4.8 \pm 2.3$ & $4.7 \pm 2.2$ & $4.3 \pm 1.9$ \\
\hline Uterine Blood Flow (ml/min) & $2.1 \pm 2.7$ & $3.5 \pm 1.8$ & $24.2 \pm 7.1^{* *}$ & $26.2 \pm 9.2$ \\
\hline Renal Blood Flow $(\mathrm{ml} / \mathrm{min})$ & $30.6 \pm 5.9$ & $33.1 \pm 6.8$ & $22.8 \pm 4.5^{*}$ & $28.7 \pm 3.8$ \\
\hline
\end{tabular}

Results ore expressed as mean $=S . D$.

$-p<.05, * P<.001$; control vs. pregnant group 
in Table VII. Estradiol exhibited a steady gradual increase throughout pregnancy and reached a peak level of twice that of control at endgestation. Estrone remained constant except for a marked increase at 40 days which returned to control values by Day 60 of gestation. There was essentially no circulating progesterone present in the nonpregnant control animals but the progesterone levels markedly increased by day 20 and continued to rise until a peak value was observed at 40 days. At the end of gestation, progesterone has declined from the peak value at 40 days but was still significantly elevated over control values.

\section{BLOOD VOLUME DATA}

Blood volume steadily increased during pregnancy reaching a peak volume of $50 \%$ above pre-pregnant values at end-gestation as seen in Table VIII. Hematocrit values were not significantly different during pregnancy, therefore indicating that total red cell volume also increases with increasing plasma volume (Figure 8 ). The blood volume and hematocrit values for the control animals are similar to previously reported normal values (16).

\section{PRESSURE-VOLUME DATA}

A recording of left ventricular pressure during continuous filling is shown in Figure 9. The curve shows the characteristic shape present when the left ventricle is filled from zero volume. Negative pressure was required to deform the ventricle and achieve complete emptying. Negative pressure and puckering of the ventricle were sought in all 
Table VII. Steroid hormone analysis data on control and pregnant guinea pigs. Results are expressed in picograms $(\mathrm{pg} / \mathrm{ml})$ or nanograms $(\mathrm{ng} / \mathrm{ml})$ of plasma.

\begin{tabular}{|c|c|c|c|c|}
\hline & \multirow[b]{2}{*}{$\begin{array}{l}\text { CONTROL } \\
(n=12)\end{array}$} & \multicolumn{3}{|c|}{ PREGNANT GROUPS } \\
\hline & & $\begin{array}{l}20-D A Y \\
(n=9)\end{array}$ & $\begin{array}{c}\triangle 0-D A Y \\
(n=9)\end{array}$ & $\begin{array}{l}60-D A Y \\
(n=13)\end{array}$ \\
\hline Estrone $(P g: m i l)$ & $29.7=8.3$ & $29.8=5.3$ & $55.7 \pm 7.1 *$ & $33.9=3.3$ \\
\hline Estradiol (pg/mi) & $22.2=8.4$ & $29.2=23.9$ & $38.9=7.5^{\star}$ & $45.5 \pm 12 . t^{\star}$ \\
\hline Progesterone $(\mathrm{ng} / \mathrm{m}$ \} & 1) $2.1=1.0$ & $105.7=56.0$ & $796.7=341.1 * \star$ & $168.4=95.1 * *$ \\
\hline
\end{tabular}


Table vill. Blood volume and hematocrit values for nompregnant control and pregnant guinea pigs.

\begin{tabular}{|c|c|c|c|c|}
\hline & \multirow[b]{2}{*}{$\begin{array}{c}(n: R O L \\
(n=14)\end{array}$} & \multicolumn{3}{|c|}{ PREGNANT GROUPS } \\
\hline & & $\begin{array}{l}20-D A Y \\
(n=10)\end{array}$ & $\begin{array}{l}40-D A Y \\
(n=13)\end{array}$ & $\begin{array}{l}60-D A Y \\
(n=13)\end{array}$ \\
\hline Blood volume $(\mathrm{mi})$ & $50.4=14.0$ & $65.2=17.6$ & $69.0=14.0 *$ & $75.8=5.5 *$ \\
\hline Hemetocrit ( :) & $35.4=2.6$ & $36.2=2.4$ & $33.3=3.9$ & $35.1 \pm 2.5$ \\
\hline
\end{tabular}

Results exfressed as mear $=$ S.D.

$\star-<.01, *:<.001$; control vs. pregnant group 
Figure 8. Total blood volume and total red cell volume during pregnancy. Blood volume data expressed as mean \pm S.D.

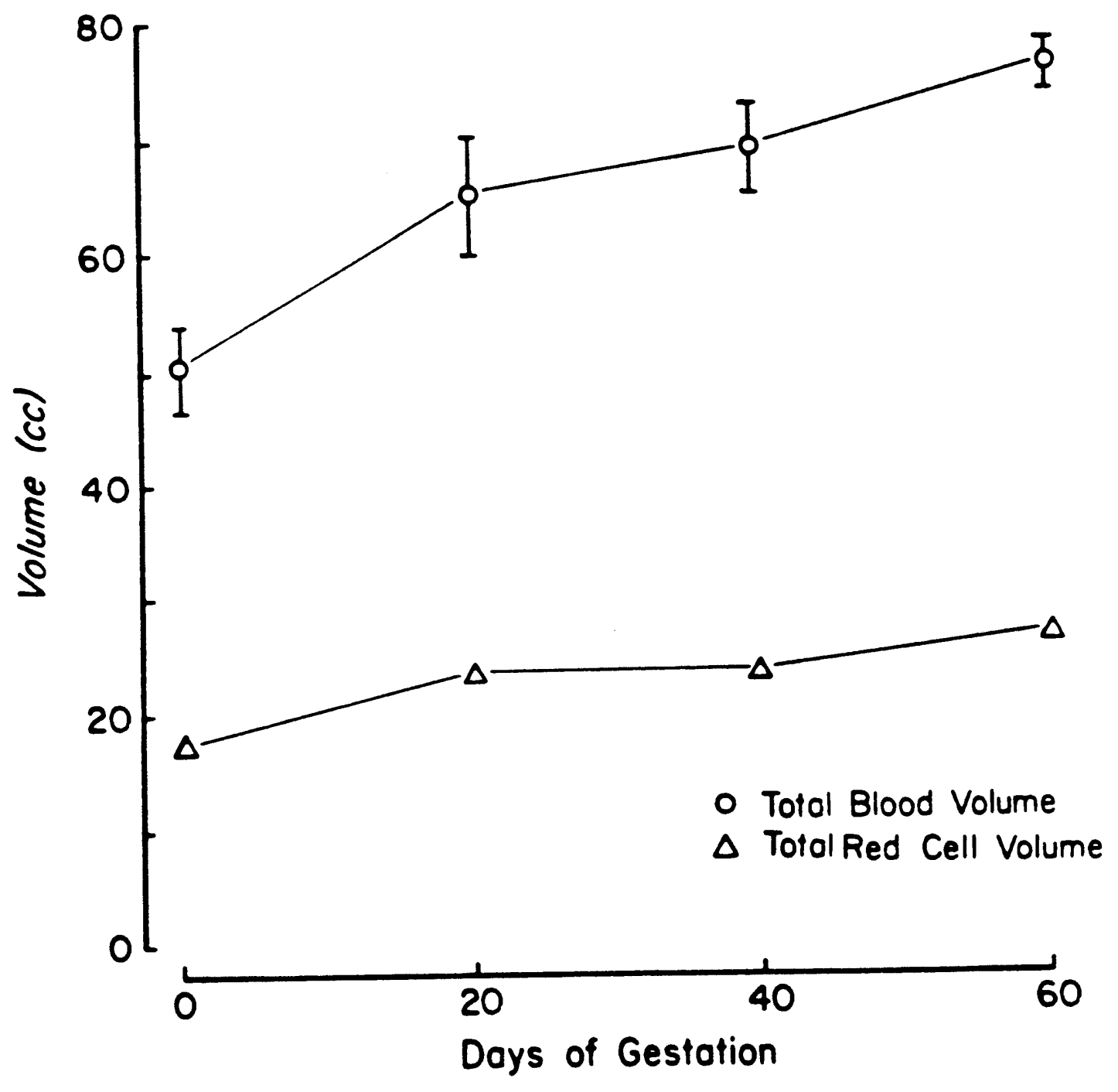


Figure 9. Intraventricular pressure was recorded during filling of the ventricle with a calibrated syringe punp. The pump was allowed to strike the syringe ot speed to avoid variable flaw during the start of infusion. When the punp was stopped, stress relaxation was evident because pressure decayed at constant volvie. Accordingly, since pressure-volvae loops showed hysteresis only the pressure-volume curve during infusion was used for analysts. Filling rate and aximum distending pressure were the same for each of the ventricles elininating differential visoelastic effects between pressure-volume relations obtained from ventricle of control or pregnant animals.

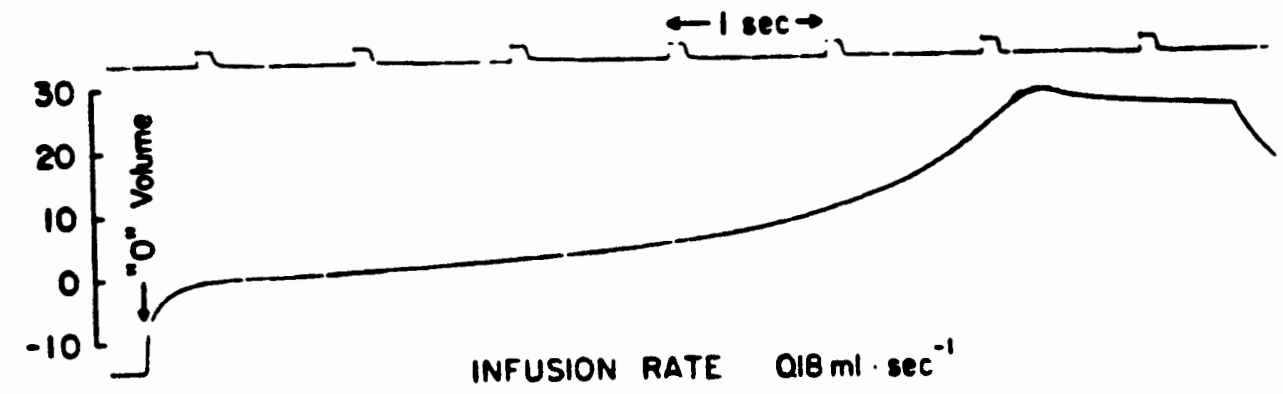


studies to assure a reproducible zero volume. The onset of filling is identified by the rapid increase volume on the record.

Ventricular pressure-volume relations are illustrated in Figures 10 and 11 . For any given left ventricular pressure, mean left ventricular volume was greater for the pregnant animals compared to the nonpregnant controls. At $8 \mathrm{~mm} \mathrm{Hg}$ distending pressure, left ventricular volume was increased by $16 \%(p<0.05)$ at Day $20,25 \%(p<0.005)$ at Day 40 and $31 \%(p<0.001)$ over nonpregnant control values by Day 60 of gestation. Since there was not a significant difference of left ventricular weights between any of the study groups, the ventricular volumes were not normalized to ventricular weight. Calculated left ventricular dimensions from a thin-wall spherical model are given in Table IX. Left ventricular radius progressively increased during pregnancy with a concomitant decrease in left ventricular wall thickness resulting in an increasing radius: wall thickness ratio throughout pregnancy.

Left ventricular mechanical and material properties were also examined. Left ventricular stiffness coefficients $\left(K_{1}\right.$ and $\left.k_{2}\right)$ were determined assuming that pressure is a monoexponential function of volume. Figure 11 shows that the log pressure-volume relationships are linear over a range of pressures. Analysis of covariance of the linear regression of the log pressure-volume relationship showed no significant difference in the slopes between the study groups (Table $X$ ). In addition, the elastic modulus was determined at constant levels of stress assuming thin-wall spherical geometry. Figure 12 demonstrates that the stress-elastic modulus relationship was linear for the nonpregnant control and pregnant animals. There was no statistical difference 
Figure 10. The in vitro left ventricular (LV) pressure volume curves of the control and pregnant guinea pigs. Results are expressed as mean \pm S.D. on the left and \pm S.E.M. on the right. 
$\begin{array}{lllllll}0 & 0 & & & & & \\ 0 & 0 & 0 & 0 & & & \\ & & 0 & 0 & 0 & & \\ & & & 0 & 0 & 0 & \\ 0 & & & & & 0 & 0\end{array}$

$44 \Delta 400$

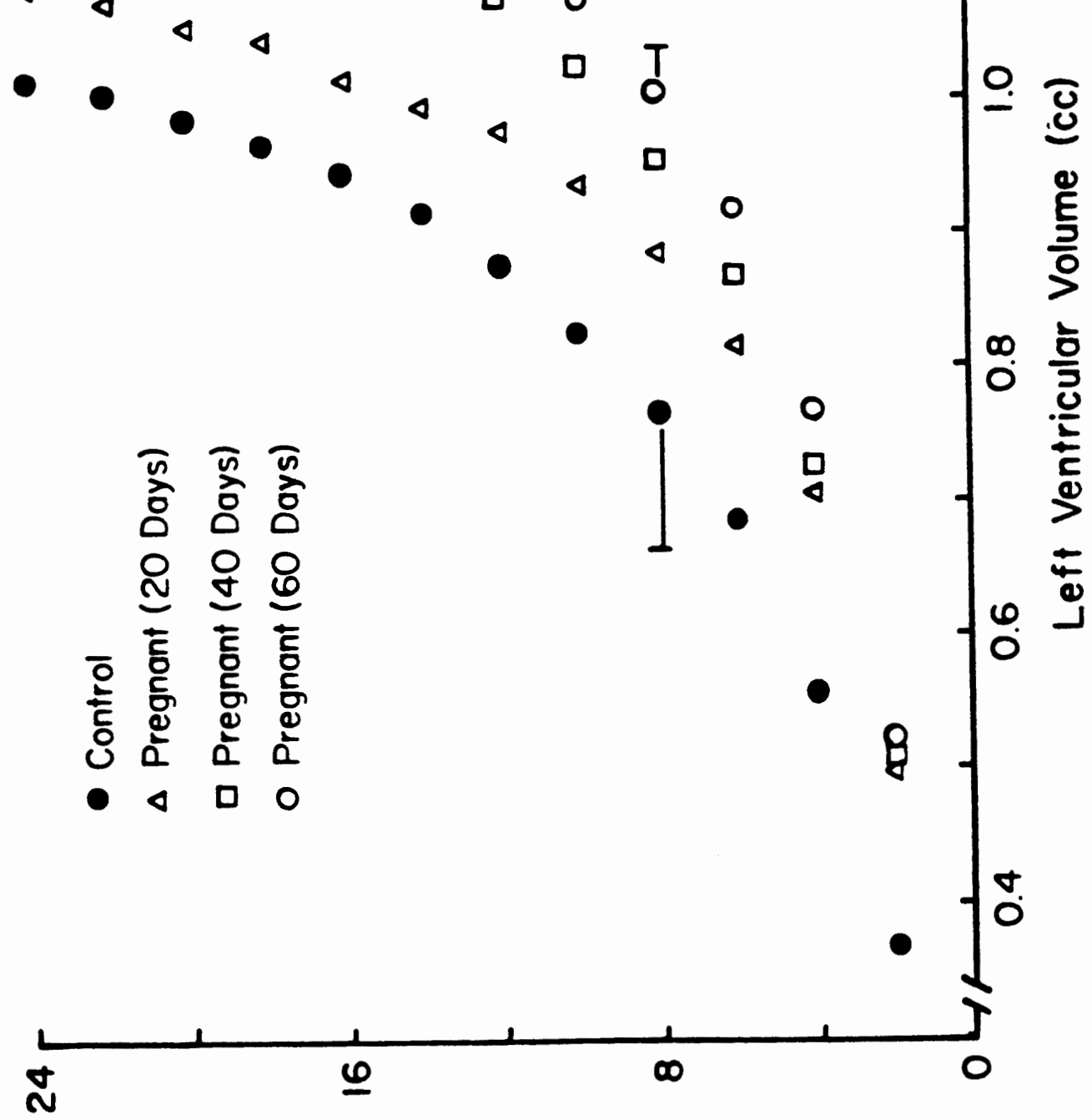

(6H ww) asnssadd 10/nग!1/ua/ 
Figure 11. Average left ventricular pressure and volume in control nonpregnant guinea pigs $(n=12)$ and in guinea pigs at Day $20(n=11)$, Day $40 \quad(n=13)$, and Day $60 \quad(n=12)$ of gestation. Pressure is displayed on a logarithmic scale from 2-24 $\mathrm{mmHg}$ to emphasize the similar slopes of the diastolic pressurevolume relationships at similar pressures. Values are expressed as mean \pm S.D. On the left and \pm S.E.M. on the right. 
ó

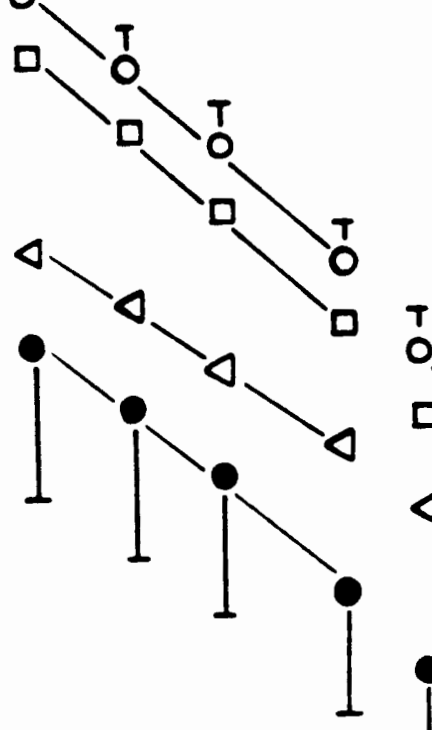

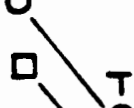<smiles>C1CCOC1</smiles><smiles>C1COCCOC1</smiles><smiles></smiles>

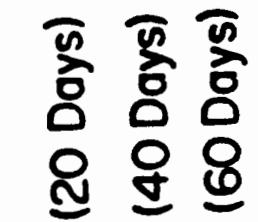

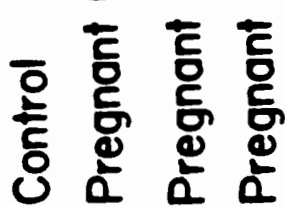

- $\triangle$ D 0

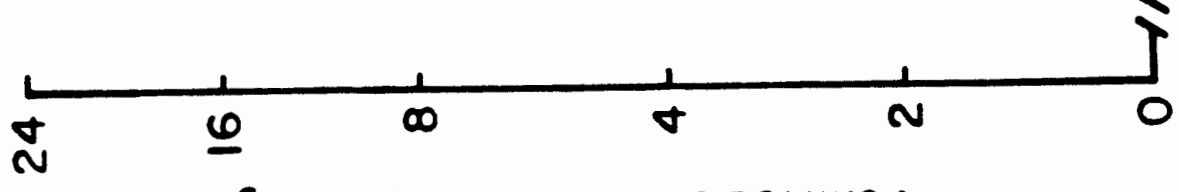

(6H wس) asnssadd 101nग!14001 
Table IX. Left ventricular dimensions at $8 \mathrm{~mm} g$ distending pressure.

\begin{tabular}{|c|c|c|c|c|}
\hline & \multirow[b]{2}{*}{$\begin{array}{c}\text { CONTROL } \\
(n=12)\end{array}$} & \multicolumn{3}{|c|}{ PREGNANT GROUPS } \\
\hline & & $\begin{array}{l}20-D A Y \\
(n=11)\end{array}$ & $\begin{array}{l}\text { 40-DAY } \\
(n=13)\end{array}$ & $\begin{array}{l}\text { 60-DAY } \\
(n=12)\end{array}$ \\
\hline LV Radius (mm) & $6.70 \pm .31$ & $7.03 \pm .18^{*}$ & $7.14 \pm .25 *$ & $7.21 \pm .19 * *$ \\
\hline LV Wall Thickness (mm) & $1.92 \pm .22$ & $1.77 \pm .21$ & $1.69 \pm .06 *$ & $1.68 \pm .17 *$ \\
\hline Radius/Wall Thickness & $3.53 \pm .52$ & $4.01 \pm .42+$ & $4.23 \pm .21 * t$ & $4.35 \pm .44 * *$ \\
\hline
\end{tabular}

Results are expressed as mean \pm S.D.

$+P<.05, * F<.025, * p_{<}<.001$; control vs. pregnant group 
Table $x$. Average slope (stiffness constants $k_{1}$ and $k_{2}$ ) from the exponential fit over the low $(2-8 \mathrm{~mm} \mathrm{Hg})$ and high (10-24 $\mathrm{mm} \mathrm{Kg})$ pressure ranges in nonpregnant control anc pregnant guinea pigs.

PREGNANT GROUPS

\begin{tabular}{lcccc}
$\begin{array}{l}\text { STIFFNESS } \\
\text { CONSTANTS }\end{array}$ & $\begin{array}{c}\text { CONTROL } \\
(n=12)\end{array}$ & $\begin{array}{l}20-D A Y \\
(n=11)\end{array}$ & $\begin{array}{l}40-D A Y \\
(n=13)\end{array}$ & $\begin{array}{l}\text { 60-DAY } \\
(n=12)\end{array}$ \\
\hline$K_{1}(2.8 \mathrm{~mm} \mathrm{Hg})$ & $3.41 \pm 2.17$ & $3.57 \pm 1.98$ & $3.04 \pm 1.86$ & $2.82=1.56$ \\
$K_{2}(10-24 \mathrm{~mm} \mathrm{Hg})$ & $4.80 \pm 3.74$ & $5.81=2.41$ & $4.09 \pm 1.96$ & $4.08 \pm 1.62$
\end{tabular}

Results are expressed as mean \pm S.D. 
Figure 12. Stress-elastic modulus as determined assuming thin-wall spherical geometry. Results are expressed as mean $=S . D$. on top and $=S$.E.M. on the bottom. 


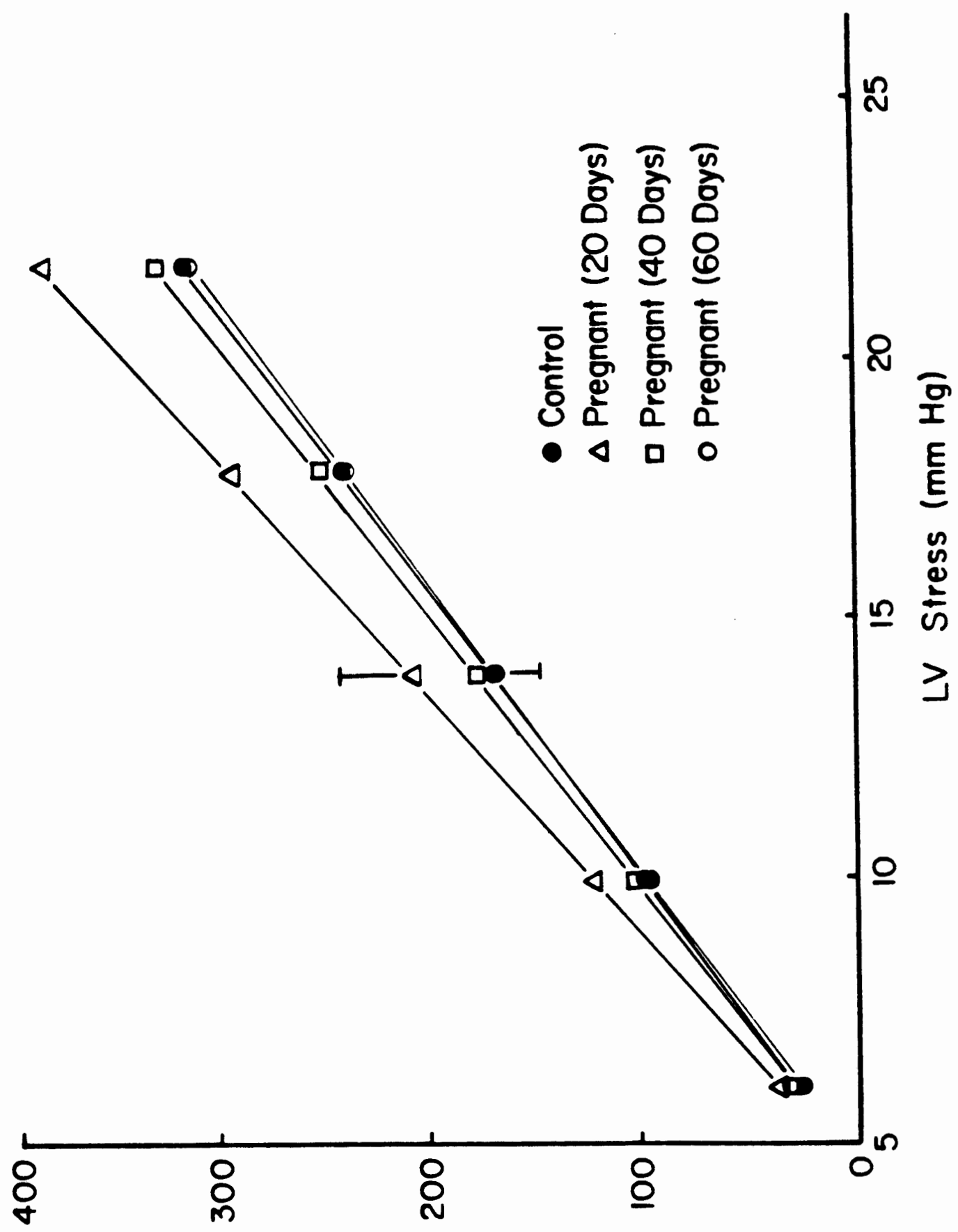

(6H w snInpow ग!15013 17 
between groups in the elastic modulus for any given level of left ventricular stress nor was there a statistical difference in the slopes of the linear relationships between the control and pregnant groups. 


\section{DISCUSSION}

During guinea pig pregnancy, cardiac output, blood volume, stroke volume and heart size are significantly increased as early as Day 20 of gestation. These alterations occur prior to an increase in uterine blood flow, which conflicts with previous theories on the mechanisms behind the cardiovascular changes which occur during pregnancy.

There is only one published study of guinea pig maternal hemodynamics investigating the changes in cardiac output during pregnancy (64). Unfortunately, this report did not use prospectively matched groups and included only five nonpregnant control animals and 14 sows of gestational ages ranging from 39 to 66 days. Unsuitability of their control group is further suggested by the significantiy greater heart and kidney weights of the five nonpregnant controls compared to the pregnant animals. The data presented in this present study demonstrates that the non-reproductive organ weights remained unchanged during pregnancy.

In order to control for maternal weight gain during pregnancy, the guinea pigs were prospectively weight-matched at Day 0 of gestation as maternal weight would be expected to return to near pre-pregnant values following delivery. Since there was no significant difference of body weights between the groups, hemodynamic data were not normalized.

It was surprising to find that cardiac output was increased as early as Day 20 of gestation. Figure 13 shows that while this increase in cardiac output occurred, stroke volume also increased as heart rate did not change from pre-pregnant levels. The significant changes in organ blood flow seen during pregnancy occurred in the reproductive 
Figure 13. Cardiac output, heart rate and stroke volume changes occurring during guinea pig pregnancy. 

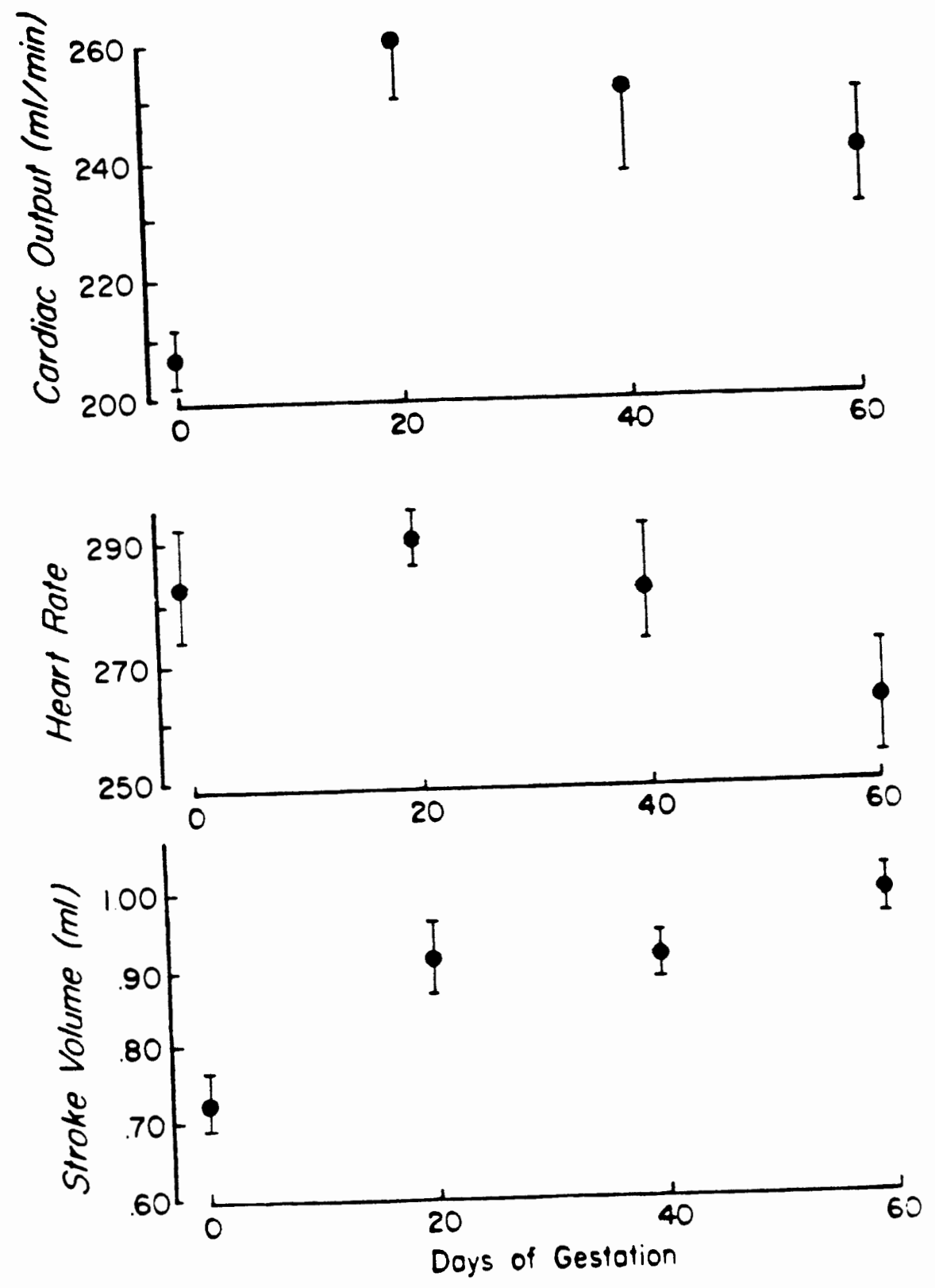
organs. Although cardiac output was up by $27 \%$ at 20 days of pregnancy, uterine blood flow did not increase until after Day 20, at which time the cardiac output fell from its peak value at 20 days and renal blood flow was reduced $25 \%$ from control values. By the end of gestation cardiac output was still continuing to fall towards pre-pregnant values while uterine blood flow essentially remained at the same level as seen at 40 days despite a significant increase in placental and fetal weight. The renal blood flow also returned to normal at the end of gestation. These changes suggest that cardiac output is increased prior to the demands of the developing reproductive burden which contradicts Burwell's analogy between the pregnant uterus and an arteriovenous fistula to explain the cardiac alterations during pregnancy.

The validation of cardiac output calculated from injection of microspheres has been performed by comparison with cardiac output maintained by a roller pump during cardiopulmonary bypass $(2,72)$. Roller pump outputs provide the most accurate reference cardiac output comparisons because they are calibrated by timed volumetric measurements. These studies have shown that determinations of cardiac output by microsphere injection were within $15 \%$, and $80 \%$ of the microsphere determinations were within $10 \%$ of the known flow. Indirect methods of measuring cardiac output with an indicator dilution dye technique (indocyanine green) have been performed $(29,72)$ simultaneously with microsphere determinations. The correlation of these two methods is not as high since the accuracy of cardiac output measurement by indicator dye techniques may be less than other techniques.

To measure the distribution of microspheres, one study employed a 
mechanical model consisting of four branching tubes perfused by a rotary pump. Effluent was collected from each branch at varying flow rates while microspheres were injected into the system. The distribution pattern was similar to the actual distribution of the flow in the system. To assess the accuracy of the microsphere method for measuring the distribution of cardiac output to individual organs, early studies used diffusable indicators with the microspheres (17). More recent comparisons have been performed utilizing electromagnetic flow transducers (8). Both studies showed a high correlation between flows measured by electromagnetic flow probes and microsphere injection.

It has been recognized that the in vitro passive pressure-volume curve is only ore of several factors that determines pressure-volume relationships of the in vivo left ventricle (24). Other factors which affect the in vivo pressure-volume curve of the left ventricle include the restraint of simultaneous pressure in the right ventricle (19), the pericardium (24), and coronary artery pressure (23). In addition, pressure-volume relations are affected in early diastole by relaxation and atrial systole may alter viscous behavior of the left ventricle at end-diastole (22). Although left ventricular in vivo pressure-volume relationships have not been studied during pregnancy, there are several hemodynamic parameters available to evaluate the effects of the above mentioned restraints on in vivo pressure-volume relations. No significant changes were observed in right or left sided filling pressure in guinea pig pregnancy which is consistent with Bader's (4) findings in human pregnancy. Systemic diastolic pressure is slightly decreased in human $(43)$ and other species $(32,52)$ during pregnancy but unchanged in 
the guinea pig. Even a modest decrease in diastolic aortic pressure would probably not reduce coronary perfusion pressure enough to alter left ventricular pressure-volume relations (23). The distensibility of the pericardium during pregnancy has not been investigated. However, it has been shown that chronic absence of the pericardium does not result in ventricular enlargement in the guinea pig. Therefore, it appears unlikely that factors affecting in vivo pressure-volume relationships during pregnancy would alter the changes in in vitro pressurevolume relations observed during guinea pig pregnancy.

Left ventricular size increased throughout pregnancy in the guinea pig. This increased ventricular size at physiological filling pressures suggests that end-diastolic volume is also increased. If there are no alterations of preload, afterload or contractility, a corresponding increase in stroke volume would then be available to augment cardiac output (see Figure 14).

Blood volume increased by $25 \%$ as early as Day 20 of pregnancy and reached a peak value of $50 \%$ above pre-pregnant levels by the end of gestation. This elevation of blood volume is similar to that observed in human pregnancy (84) although the guinea pig did not exhibit dilutional anemia as seen in humans (76) as total red cell volume expanded proportionally with plasma volume during the guinea pig pregnancy. Rightsided filling pressures did not change in either guinea pig or human pregnancy.

Measurements of ventricular compliance, and particularly measurements giving an index of intrinsic stiffness are of interest because they are important determinants of cardiac performance both in normal 
Figure 14. This figure illustrates the \% change from nonpregnant control values of stroke volume and heart size during pregnancy.
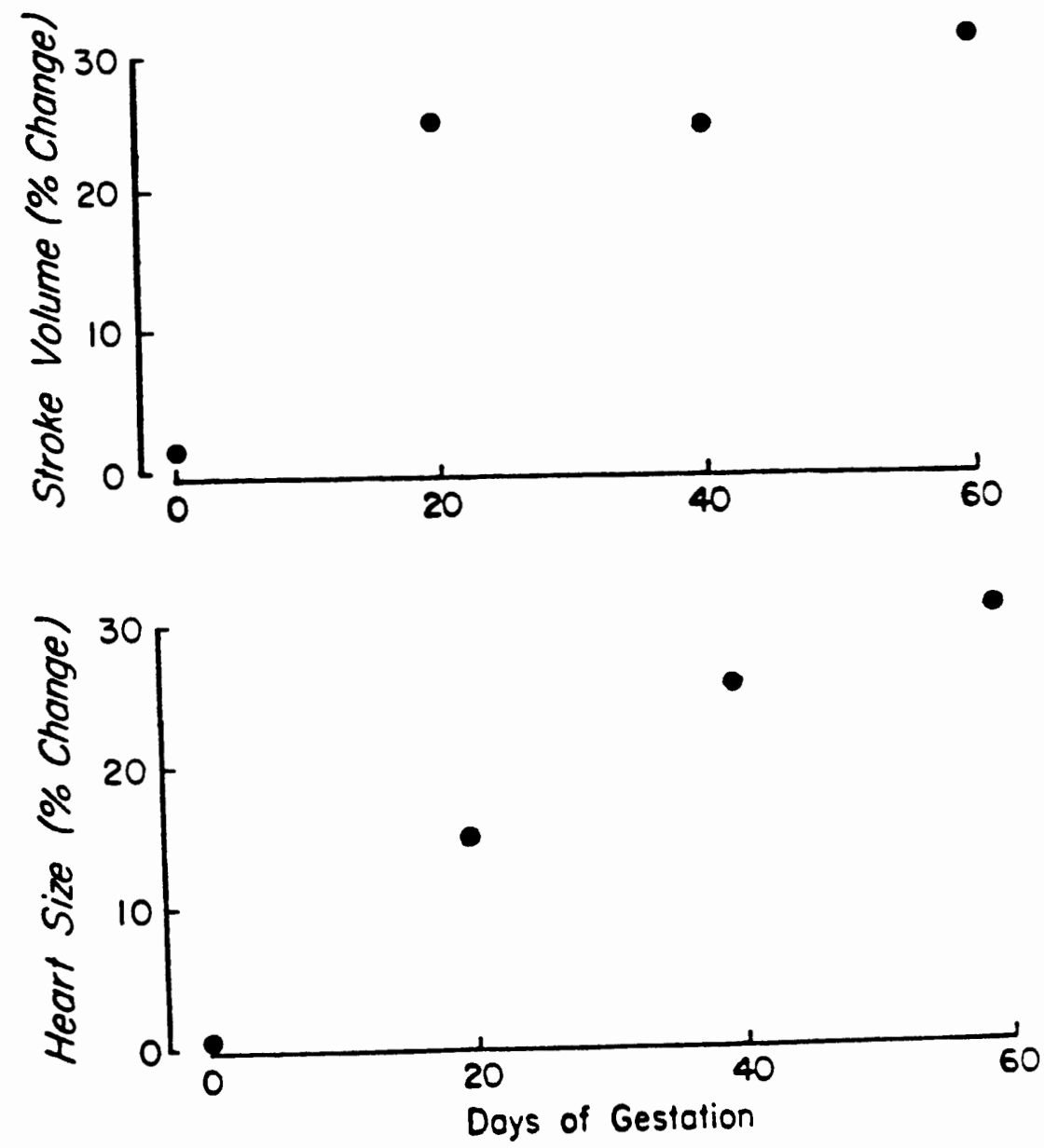
and pathological states (7). Simultaneous measurements of intraventricular pressure and volume alone do not provide all the information to completely assess the intrinsic stiffness of the left ventricle. In order to calculate elastic modulus (E) as a function of wall stress $(\sigma)$, the thickness and curvature of the ventricle in one spot must be known or a geometrical model must be used to calculate the wall thickness and ventricular volume (57).

The actual geometry of the ventricle is quite complicated because the ventricular wall is composed of both muscle and connective tissue with the muscle fibers arranged in overlapping spiral patterns. During systole, the direction of the local stresses developed in the ventricular wall are different in the several layers of muscles, but roughly of uniform magnitude because the intrinsic structure of the myofibrils throughout the ventricle. Though the ventricle is not spherical nor thin-walled, the thin-wall spherical model is based on the assumption that the ventricle is thick in regions where the radius of curvature is large and thin in regions where it is small, thus keeping the local stress applied to the ventricular wall approximately constant. The law of Laplace, which assumes that only tensile forces are applied to any element of material and that the stress is constant across the thickness of the wall, may be applied to the dimensions of fixed ventricles to calculate principal stresses at a variety of points (34). This principle was first used by Woods in 1892 (90) for canine hearts and more recently used for the hearts of guinea pigs, rats, rabbits, hogs and calves (47).

Others have suggested that use of the more mathematically 
complicated thick-wall ventricular models in which stress is allowed to vary across the wall $(81,89)$. These models take into account bending stresses in addition to tensile stresses produced by ventricular configurational changes during filling. There are now a number of investigations which compare the thick-wall and thin-wall models (30, $51,56)$. These studies provide evidence which supports the conclusion by McHale and Greenfield (51) that a thin-wall (Laplace) model of the left ventricle permits calculation for both systole and diastole which are within $10 \%$ of the value given by the thick-wall model. As demonstrated earlier by Figure 12, important changes in compliance and elasticity of ventricular muscle were not present during guinea pig pregnancy. A change in geometry rather than material properties is further supported by the similar slopes of the monoexponential fits to the pressure-volume curves as seen in Figure 11. Together with the fact that contractility does not seem to change during pregnancy (35), this evidence supports the belief that left ventricular enlargement is the dominant mechanism which leads to increased stroke volume during pregnancy.

The mechanism by which left ventricular enlargement occurs still remains unclear. An earlier study suggested that increased circulating estrogen levels may be responsible for some of the cardiovascular alterations seen during pregnancy (31). Figure 15 demonstrates that estrogen levels in the guinea pig pregnancy are not significantly elevated by the time most of the cardiovascular changes take place at 20 days. Progesterone levels are significantly elevated by 20 days suggesting that progesterone may be involved in increasing venous compliance (20) 
Figure 15. Steroid hormone levels during pregnancy. Results are expressed as mean \pm S.E.M. 

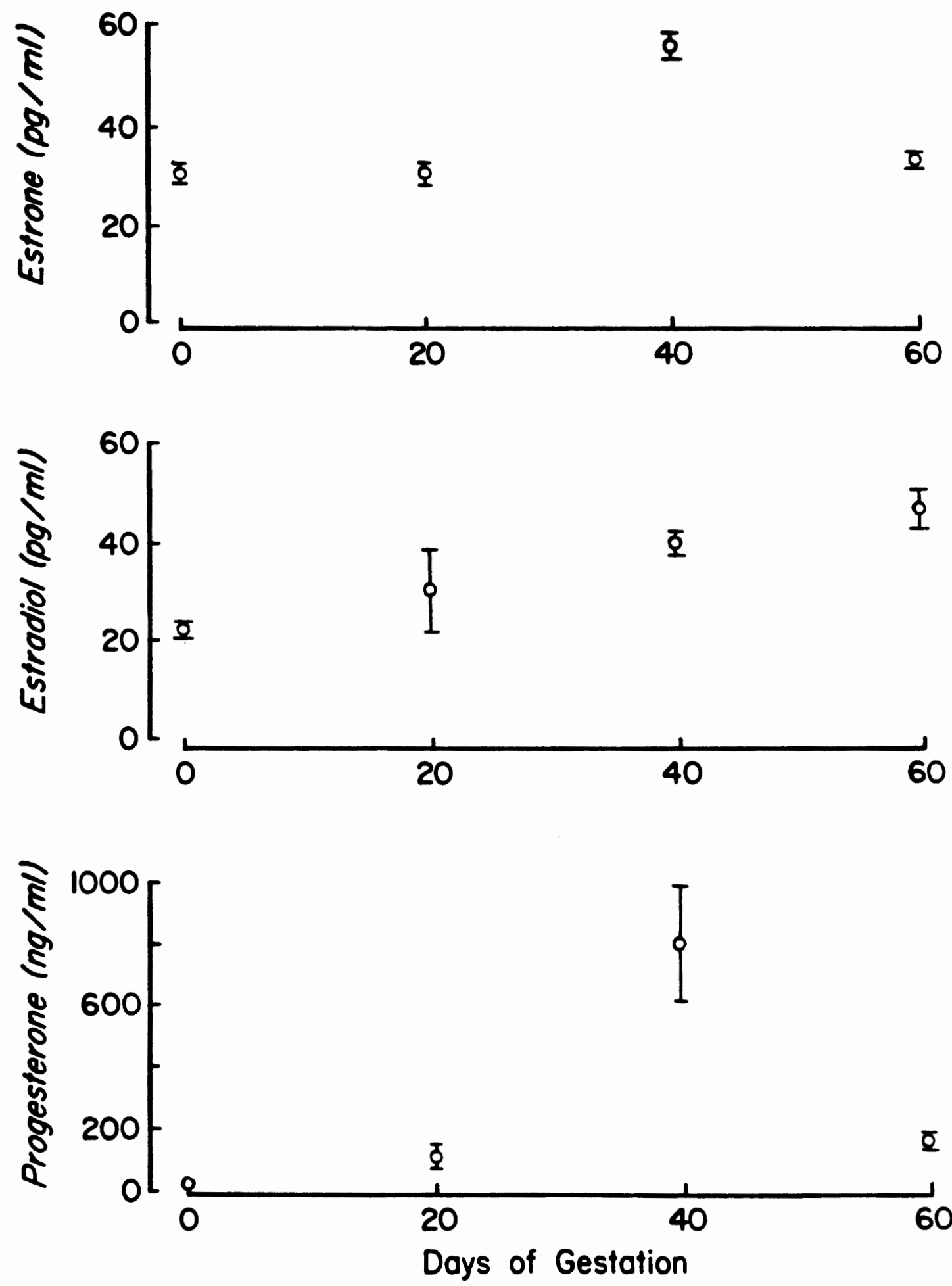
thereby reducing peripheral resistance which could account for the absence of an elevation in systemic blood pressure despite a significant increase in cardiac output.

Even though circulating levels of estrogen are not significantly increased by Day 20 of gestation, this does not rule out the possibility that estrogen is involved in the cardiovascular changes which are taking place diring the first 20 days of pregnancy. Further studies are needed to investigate the tissue levels, binding affinity, and locality of estrogen receptor sites during guinea pig pregnancy to fully understand the role of estrogen in mediating some of the cardiovascular a)terations during gestation. 


\section{SUMMARY}

Maternal cardiovascular adaptations appear to be essential in order to supply extra circulation to both the developing fetus and maternal system during a successful pregnancy. Since inadequate cardiovascular adjustments may produce abortions or maternal morbidity, the characterization of maternal cardiovascular changes during pregnancy and the elaboration of the underlying mechanism for these changes are essential to the understanding of how the heart enlarges during pregnancy and what significance this enlargement might have. To provide needed information regarding this time course and extent of maternal cardiac enlargement and the hormonal and hemodynamic changes which may be responsible for these changes, the guinea pig was used as an animal model to characterize the maternal cardiac, hemodynamic and hormonal changes during early, mid and late pregnancy.

All animals used were virgin female guinea pigs which were prospectively weight-matched and randomly assigned to one of the following groups: 1) Control, 2) Pregnant (20 Days), 3) Pregnant (40 Days), and 4) Pregnant (60 Days). The sows assigned to the pregnant groups were housed with a boar during estrus to provide a dated pregnancy. On the day of study, each animal was anesthetized and polyvinyl catheters were placed in the left ventricle, right atrium and abdominal aorta. The animals were allowed to recover from the anesthesia and were then placed in a limited restraint cage where simultaneous pressures were recorded. Cardiac output and regional blood flows were then measured by radioactive microspheres indicator dilution technique, arterial blood gas samples were taken, blood volume was measured by 
a dye dilution technique using Evans Blue, and estrogen and progesterone plasma levels were determined by radioimmunoassay. After all in vivo measurements were obtained, the animals were sacrificed and the in vitro left ventricular pressure-volume relations were measured in 14 control and 39 pregnant guinea pigs.

Arterial blood gases and hematocrits obtained at the end of the study were similar to those previousiy reported in control animals. Kidney weights, wet lung weights and left ventricular weights were unchanged during pregnancy despite a significant increase in total maternal weight. Hemodynamic data from the control and pregnant guinea pigs demonstrated that there was no statistical difference in heart or respiratory rates, or in aortic, right atrial or left ventricular end-diastolic pressures. Total cardiac output was increased as early as Day 20 of gestation but then gradually returned to pre-pregnant values. Uterine blood flow was not increased until Day 40 when fetal and placental weights were increased. Since heart rates were unchanged, stroke volume was increased by Day 20 and remained elevated throughout pregnancy. Blood volume steadily increased during pregnancy, reaching a peak value at the end of gestation. The in vitro pressure-volume relationships of the left ventricles demonstrated that the curves of the pregnant animals were shifted to the right as early as Day 20 and progressively increased with a peak increase in volume occurring at end gestation. This increase occurred without a change in left ventricular weight, therefore increasing the radius:wall thickness ratio throughout pregnancy. There was no change in left ventricle mechanical or material properties indicating that left ventricular enlargment occurs by 
geometric remodeling. Estradiol plasma levels slowly increased during pregnancy but were not significantly elevated until Day 40 of gestation. Estrone was only elevated at Day 40 and returned again by Day 60 , while progesterone was significantly increased throughout pregnancy with a peak value occurring at Day 40 .

In summary, significant cardiovascular changes are seen during early pregnancy and occur prior to a major increase in uterine blood flow. These cardiovascular alterations may be mediated by changing hormone levels. 


\section{REFERENCES}

1. Adams JQ: Cardiovascular physiology in normal pregnancy: Studies with the dye dilution technique. Am J Obstet Gynecol 67: $741,1954$.

2. Archie JP, DE Fixler, DJ Ullyot: Measurements of cardiac output and organ trapping of radioactive microspheres. J Appl Physiol 35: 148, 1973.

3. Assali NS, L Rauramo, T Peltonen: Measurement of uterine blood flow and uterine metabolism. VIII. Uterine and fetal blood flow and oxygen consumption in early human pregnancy. Am J Obstet Gynecol 79: 68, 1960.

4. Bader RA, ME Bader, DJ Rose, E Braunwald: Hemodynamics at rest and during exercise in normal pregnancy as studied by cardiac catheterization. $\mathrm{J} \mathrm{Cl}$ in Invest $34: 1524,1955$.

5. Barcroft J, JA Kennedy, MF Mason: The blood volume and kindered properties in pregnant sheep. J Physiol 95: 159, 1939.

6. Bar-Ilan A, J Marder: Acid base status in unanesthetized, unrestrained guinea pigs. Pflügers Arch 384: 93, 1980.

7. Braunwald E, J Ross: The ventricular end-diastolic pressure. Am $\mathrm{J}$ Med 34: 147, 1963.

8. Buckberg GD, JC Luck, DB Payne, JIE Hoffman, JP Archie, DE Fixler: Some sources of error in measuring regional blood flow with radioactive microspheres. J Appl Physiol 31: 598, 1971.

9. Burg, JR, A Dodek, FE Kloster, J Metcalfe: Alterations of systolic time intervals during pregnancy. Circulation 49: 560, 1974.

10. Burggraf GW, J0 Parker: Effects of dextran infusion on left ventricular volume and pressure in man. Cathet Cardiovasc Diag 4: $383,1978$.

11. Burns JW, JW Covell, J Ross: Mechanics of isotonic left ventricular contractions. Am J Physiol 224: 357, 1973.

12. Burwell CS, WD Strayhorn: Observations on the circulation during and after pregnancy. $\mathrm{J} \mathrm{Cl}$ in Invest 12: 977, 1933.

13. Burwel1 CS, WD Strayhorn, D Flickenger, MB Corletter, EP Bowerman, JA Kennedy: Circulation during pregnancy. Arch Int Med 62: $979,1938$. 
14. Burwell CS: The placenta as a modified arteriovenous fistula, considered in relation to the circulatory adjustments to pregnancy. Am J Med Sci 195(1): 1, 1938.

15. Challis JRG, RB Heap, DV Illingworth: Concentrations of estrogen and progesterone in the plasma of nonpregnant, pregnant and lactating guinea pigs. J Endocrinol 51: 333, 1971.

16. Constable BJ: Changes in blood volume and blood picture during the life of the rat and guinea pig from birth to maturity. J Physiol 167: 229, 1963.

17. Delaney JR, E Grimm: Canine gastric blood flow and its distribution. Am J Physiol 207: 1195, 1964.

18. DeMaria AN, A Neumann, G Lee, W Fowler, DT Mason: Alterations in ventricular mass and performance induced by exercise training in man evaluated by echocardiography. Circulation 57 (2): 237,1978 .

19. Elzinga $G, R$ van Grondelle, $N$ Westerhof, $G C$ van der Bos: Ventricular interference. Am J Physiol 226: 941, 1974.

20. Fawer R, A Dettling, D Weihs, $H$ Welti, JL Schelling: Effect of the menstrual cycle, oral contraception and pregnancy on forearm blood flow, venous distensibility and clotting factors. Europ J Clin Pharmacol 13: 251, 1978.

21. Fletcher PJ, JM Pfeffer, MA Pfeffer, E Braunwald: Left ventricular diastolic pressure-volume relations in rats with healed myocardial infarction. Circ Res 49: 618, 1981.

22. Gaasch WH, JS Cole, MA Quinones, JK Alexander: Dynamic determinants of left ventricular pressure-volume relations in man. Circulation 51: 317, 1975.

23. Gaasch WH, OHL Bing, MB Pine, A Franklin, J Clement, D Rhodes, WP Phear, RM Weintraub: Myocardial contracture during prolonged ischemic arrest and reperfusion. Am J Physiol 235(6): H619, 1978.

24. Glantz SA, WW Parmley: Factors which affect the diastolic pressurevolume curve. Circ Res 42: 171, 1978.

25. Gleason WL, E Braunwald: Studies on Starling's law of the heart. VI. Relationship between left ventricular end-diastolic volume and stroke volume in man. Circulation 25: 841, 1962.

26. Goodrich SM, JE Wood: The effect of estradiol-17B on peripheral venous distensibility and velocity of venous blood flow. Am J Obstet Gynecol 96(3): 407, 1966. 
27. Heymann MA, BD Payne, JE Hoffman, AM Rudolph: Blood flow measurements with radionuclide labeled particles. Prog Cardiovasc Dis 20(1): $55,1977$.

28. Hohimer AR, MJ Morton, J Metcalfe: Maternal hemodynamics during guinea pig pregnancy. Physiologist 23: 148, 1980.

29. Hoffbrand BI, RP Forsyth: Validity studies of the radioactive microsphere method for the study of the distribution of cardiac output, organ blood flow, and resistance in the conscious rhesus monkey. Cardiovasc Res 3: 426, 1969.

30. Hood WP, MJ Thompson, CE Rackley, EI Rolett: Comparison of calculations of left ventricular wall stress in man from thinwalled and thick-walled ellipsoidal models. Circ Res 24: $575,1969$.

31. Hosenpud JD, MV Hart, MJ Morton, AR Hohimer: Chronic estrogen administration increases left ventricular size and stroke volume. Clin Res 31(2): 192A, 1983.

32. Hoversland AS, JT Parer, J Metcalfe: Hemodynamic adjustments in the pygmy goat during pregnancy and early postpartum. Biol Reprod 10: 578, 1974.

33. Hytten FE, DB Paintin: Increase in plasma volume during pregnancy. J Obstet Gynecol (BC) 70: 402, 1963.

34. Kane RL, TA McMahon, RL Wagner, WH Abelman: Ventricular elastic modulus as a function of age in the Syrian Golden hamster. Circ Res 38(2): 74, 1976.

35. Katz R, JS Karlinger, R Resnik: Effects of a natural volume overload state (pregnancy) on left ventricular performance in normal human subjects. Circulation 58(3): 434, 1978.

36. King TM, WV Whitehorn, B Reeves: Effects of estrogen composition and function of cardiac muscle. Am J Physiol 196: 1282, 1959.

37. Kutscher C: Plasma volume changes during water-deprivation in gerbils, hamsters, guinea pigs and rats. Biochem Physiol 25: $929,1968$.

38. Laird-Meeter K, G Van Deley, TH Bom, JW Wladimiroff, J Roelandt: Cardiovascular adjustments during pregnancy. An echocardiographic study. Clin Cardiol 2: 328, 1979.

39. Lehtovirta P: Haemodynamic effects of combined oestrogen/progesterone oral contraceptives. J Obstet Gynecol (BC) 81:517, 1974. 
40. Lehtovirta P: Peripheral hemodynamic effects of combined oestrogen/progesterone oral contraceptives. J obstet Gynecol (BC) 81: 526,1974 .

41. Lindhard J: Über das Minutevolum des Herzens bei Ruhe und Muskelarbeit. Arch $f d$ ges Physiol 161: 233, 1915.

42. Macdonald A: The Bearings of Chronic Disease of the Heart on Pregnancy, Parturition and Childbed with papers on puerperal pluerol pneumonia and eclampsia. London: J \& A Churchill, 1878.

43. MacGillvray I, GA Rose, B Rowe: Blood pressure survey in pregnancy. Clin Sci 37: 395, 1969.

44. Mahler F, J Ross, RA O'Rourke, JW Covell: Effe-ts of changes in prelaod, afterload and inotropic state on ejection and isovolumic phase measurements of contractility in the conscious dog. Amer J Cardiol 35: 626, 1975.

45. Malik AS, JE Kaplan, TM Saba: Reference sample method for cardiac output and regional blood flow determinations in the rat. J Appl Physiol 40(3): 472, 1976.

46. Malinow MR, JA Moguilevsky, B Lema, GE Bur: Vascular and extravascular radioactivity after injection of estradiol in the human being. J Clin Endocrinol Metab 23: 306, 1963.

47. Martin CE, JA Shaver, ME Thompson, PS Reddy, JJ Leonard: Direct correlation of external systolic time intervals with internal indices of left ventricular function in man. Circulation 44: $419,1971$.

48. McGill HC, PJ Sheridan: Nuclear uptake of sex steroid hormones in the cardiovascular system of the baboon. Circ Res 48(2): 238,1981 .

49. MCGill HC, VC Anselmo, JM Buchanan, PJ Sheridan: The heart is a target organ for androgens. Science 207: 775, 1980.

50. MCCullagh WH, JW Covell, JR Ross: Left ventricular dilatation and diastolic compliance changes during chronic volume overloading. Circulation 95: 943, 1972.

51. McHale PA, JC Greenfield: Evaluation of several geometric models for estimation of left ventricular wall stress. Circ Res 33: $303,1973$.

52. Metcalfe J, JT Parer: Cardiovascular changes during pregnancy in ewes. Am J Physiol 210: 821, 1966. 
53. Metcalfe J, SL Romney, LH Ramsey, DE Reid, CS Burwell: Estimation of uterine blood flow in normal human pregnancy at term. $\mathrm{J} \mathrm{Cl}$ in Invest 34: 1632, 1955.

54. Metzger CC, CBC Hough, FW Kroetz, JJ Leonard: True isovolumic contraction time: Its correlation with two external indexes of ventricular performance. Am J Cardiol 25: 434, 1970.

55. Milnor WR: Arterial impedance as ventricular afterload. Circ Res 36(5): $565,1975$.

56. Mirsky I: Left ventricular stresses in the intact human heart. Biophys J 9: 198, 1969.

57. Mirsky I, WW Parmley: Assessment of passive elastic stiffness for isolated heart muscle and the intact heart. Circ Res 33: $233,1973$.

58. Morales PD, RL Wagner, WH Abelman: Right and left ventricular compliance in experimental acute and subacute trypansoma myocarditis. Cardiovasc Res 7: 201, 1973.

59. Morganroth J, BJ Maron, WL Henry, SE Epstein: Comparative left ventricular dimensions in trained athletes. Ann Int Med 82(4): $521,1975$.

60. Morton MJ, AR Hohimer, J Metcalfe: Maternal left ventricular adaptations to pregnancy. Clin Res 28: 11A, 1980.

61. Neutze JM, F Wyler, AM Rudolph: Use of radioactive microspheres to assess distribution of cardiac output in rabbits. Am J Physiol 215: 486, 1968.

62. Parker J0, RB Case: Normal left ventricular function. Circulation $60: 4,1979$.

63. Patterson SW, EH Starling: On mechanical factors which determine the output of the ventricles. J Physiol 48: 357, 1914.

64. Peeters LLH, G Grutters, CB Martin: Distribution of cardiac output in the unstressed guinea pig. Am J Obstet Gynecol 138: $1177,1980$.

65. Phillips DS: Basic Statistics for Health Sciences Students. San Francisco: WH Freeman and Co., 1978, pp. 93-99.

66. Pritchard JA: Changes in blood volume during pregnancy and delivery. Anesthesiology 26: 393, 1965.

67. Resko JA, MJ Koering, RW Goy, CH Phoenix: Preovulatory progestins: Observations on their source in Rhesus monkeys. $\mathrm{J} C l$ in Endocrinol Metab 41(1): 120, 1975. 
68. Resko JA, JG Ploem, HL Stadelman: Estrogens in fetal and maternal plasma of the Rhesus monkey. Endocrinology 97(2): 425, 1975.

69. Roeske WR, RA O'Rourke, A Klein, G Leopold, JS Karlinger: Noninvasive evaluation of ventricular hypertrophy in professional athletes. Circulation 53(2): 286, 1976.

70. Ross J: Adaptations of the left ventricle to chronic volume overload. Circ Res 34/35 (Supp 1): 11, 1974.

71. Rubler $S, R$ Schneebaum, $N$ Hammer: Systolic time intervals in pregnancy and the postpartum period. Amer Heart $J$ 86(2): $182,1973$.

72. Rudy LW, MA Heymann, LH Edwards: Distribution of systemic blood flow during cardiopulmonary bypass. J Appl Physiol 34: $194,1973$.

73. Sanghvi VR, AL Mark, F Khaja, JO Parker: Effects of blood volume expansion on left ventricular hemodynamics in man. Circulation 46: 780, 1972.

74. Sasaki $Y$, HN Wagner: Measurement of the distribution of cardiac output in unanesthetized rats. J Appl Physiol 30: 879, 1971.

75. Schreiner GE, N Freinkel, JW Athens, W Stone: Cardiac output, central volume, and dye injection curves in traumatic arteriovenous fistulas in man. Circulation 7: 718, 1953.

76. Scott DE: Anemia in pregnancy. In: Obstetrics and Gynecology Annual: 1972, edited by RM Wynn. New York: AppeltonCentury-Crofts, 1972, pp. 219-244.

77. Snedecor GW, WG Cochran: Statistical Methods, 6th ed. Ames, Iowa: Iowa State University Press, 1967, pp. 115, 178, 302-303, $433-436,460-465$.

78. Sonnenblick EH, SE Downing: Afterload as a primary determinant of ventricular performance. Am J Physiol 204: 604, 1963.

79. Stander HJ, EE Duncan, WE Sisson: Heart output during pregnancy. J Obstet Gynecol 11: 44, 1926.

80. Stander HJ, JF Cadden: The cardiac output in pregnant women. Amer J Obstet Gynecol 24: 13, 1932.

81. Streeter DD, RH Vaishnav, DJ Patel: Stress distribution in the canine left ventricle during diastole and systole. Biophys $\mathrm{J}$ 10: $345,1970$. 
82. Stumpf WE, M Sar, G Aumuller: The heart: A target organ for estradiol. Science 196: 319, 1977.

83. Ueland K, MJ Novy, EN Peterson, J Metcalfe: Maternal cardiovascular dynamics. IV. The influence of gestational age on the maternal cardiovascular response to posture and exercise. Am J Obstet Gynecol 105: 856, 1969.

84. Ueland K, JT Parer: Effects of estrogens on the cardiovascular system of the ewe. Am J Obstet Gynecol 96: 400, 1966.

85. Walters WAW, YL Lim: Cardiovascular dynamics in women receiving oral contraceptive therapy. Lancet 2: 879, 1969.

86. Walters WAW, YL Lim: Haemodynamic changes in women taking oral contraceptives. J Obstet Gynecol (BC) 77: 1007, 1970.

87. Wang L: Plasma volume, cell volume, total volume and $F$ cells factor in the normal and splenectomized Sherman rat. Am $J$ Physiol 196(1): 188, 1959.

88. Weissler AM, RG Peeler, WH Roehill: Relationship between left ventricular ejection time, stroke volume, and heart rate in normal individuals and patients with cardiovascular disease. Am Heart J 62: 367, 1961.

89. Wong AYK, PM Rautaharju: Stress distribution within the left ventricular wall approximated as a thick ellipsoidal shell. Am Heart J 75: 649, 1968.

90. !oods RH: A few applications of a spherical theorem to membranes in the human body in a state of tension. J Anat Physiol 26: 3E2, 139?.

91. Bedford CA, JRG Challis, FA Harrison, RB Heap: The role of oestrogens and progesterone in the onset of parturition in various species. J Reprod Fert Suppl 16: 1, 1972. 